\title{
EXPERIMENTAL AND NUMERICAL STUDY OF MECHANICAL PROPERTIES FOR THE DOUBLE-RIBBED REINFORCED BEAM-COLUMN CONNECTION
}

\author{
Hong-Wei Ma ${ }^{1}$, Hao Zheng ${ }^{1}$, Wei Zhang ${ }^{1,2 *}$ and Zhan-zhan Tang ${ }^{1,2}$ \\ College of Civil Science and Engineering, Yangzhou University, Yangzhou, China \\ ${ }^{2}$ Institute of Theoretical and Applied Mechanics, Czech Academy of Sciences, Prague, Czech Republic \\ *(Corresponding author: E-mail: zhangwei621@gmail.com)
}

\section{A B S T RA C T}

This paper investigates the hysteretic behavior of steel reinforced beam-column connections with or without double-rib and optimizes the reinforced ribs of these connections under cyclic loading. The objective is to give a reasonable range of double-ribs' size and fracture behavior of the weld at beam-column connections. Two specimens (the conventional beam-column connection and the double-ribbed reinforced beam-column connection) are designed and tested under cyclic loads. Meanwhile, the finite element models of these two kinds of connections are established. The hysteretic performance and damage evolution of the connections, such as the failure modes, hysteretic curves, skeleton curves, stiffness degradations, ductility, and energy dissipation capacities, are analyzed and verified. Moreover, fifteen numerical models with different lengths of the line $\left(l_{a}\right)$, the width $(b)$, and the thickness $\left(t_{s}\right)$ of reinforced ribs are established for parametric study. The results show that double-ribs can improve the strength and ductility of the connection. And the FE predictions agree well with the experimental results. The reasonable parameters of reinforced ribs of double-ribbed reinforced beam-column connection are proposed

\section{ARTICLE HISTORY}

$\begin{array}{ll}\text { Received: } & \text { 21 March } 2020 \\ \text { Revised: } & \text { 31 May } 2020 \\ \text { Accepted: } & \text { 22 June } 2020\end{array}$

\section{KE Y W O R D S}

Double-ribbed;

Beam-column connections;

Steel;

Hysteretic behavior

\section{Introduction}

The lateral stiffness of a steel frame depends on the strength and ductility of beams, columns, and beam-column connections. Therefore, these connections should be rigid connections [1]. It has been reported in some literature that during the Northridge earthquake in the United States in 1994 and the Kobe earthquake in Japan in 1995, brittle damage occurred in many rigid beam-column connections of steel moment frames [2-4]. To avoid the seismic vulnerability of steel beam-column connections, the seismic design principle of "strong column weak beam and strong connection weak member" [5-6] in the Chinese code is proposed.

Based on the above seismic design principle, the solution of moving the beam plastic hinge away from the column is proposed by weakening or reinforcing the connections. Over the years, numerous studies on the mechanical performance of steel beam-column connections with reduced beam sections have been carried out in the references [7-14]. In comparison, relatively few studies [15-21] on the mechanical properties of beam-column connections with the reinforcement of steel frames have been performed, and there are especially few results concerning double-ribbed reinforced beam-column connections. Besides, those studies mainly focused on the mechanical performance of the connections themselves without considering the difference in rib size, which may affect the fracture behavior of the connections. As a result, the major objective of this study is to build and verify the finite element (FE) models of double-ribbed reinforced beam-column connections by comparing the experimental and numerical results and to optimize the parameters of reinforced ribs by analyzing the stress triaxiality index $\left(R_{\sigma}\right)$, equivalent plastic strain index (P.I.) [22], cracking index (R.I.) [23], and cracking development of these connections [24].

To achieve a deep understanding of the hysteretic behavior and the reasonable parameters of the ribs of double-ribbed reinforced connections, two full-scale connection specimens are designed and fabricated, which are assembled and tested under cyclic loads. Of the two specimens, one has two reinforced ribs, and the other is a conventional connection. Meanwhile, two FE models are established for the above two specimens. These specimens and numerical models are used to study the hysteretic behavior, such as the plastic hinge positions, hysteresis curves, failure modes, load-bearing capacities, ductility capacities, stiffness degradations, coefficient curves, and damage curves. They are also used to verify the FE models by comparing with each other.

Furthermore, fifteen FE models with different rib sizes are established and analyzed to discuss the stress triaxiality ratio $\left(R_{\sigma}\right)$, plastic equivalent strain index (P.I.), and cracking index (R.I.). Based on the benefits or accelerated failure found through analyzing the fracture behavior, the parameters of these connections are optimized. The results can provide supportive data and a theoretical basis for the design of symmetric double-ribbed reinforced connections

\section{Experimental program}

\subsection{Specimen Design}

Two specimens of beam-column connections of a steel frame are designed, including one normal beam-column connection (NBN) for experimental verification and one double-ribbed reinforced beam-column connection (RRN).They are fabricated using Q345B structural steel. The beam, column, and stiffener are welded with an E5015 electrode and full penetration groove welding, while the shear plate and beam web are connected by 4-M20 high strength bolts (the performance grade of these bolts is 8.8). The section dimensions of the beam and column are HN $248 \mathrm{~mm} \times$ $124 \mathrm{~mm} \times 5 \mathrm{~mm} \times 8 \mathrm{~mm}$ and HW $250 \mathrm{~mm} \times 250 \mathrm{~mm} \times 9 \mathrm{~mm} \times 14 \mathrm{~mm}$, respectively, and the shear plate is $170 \mathrm{~mm} \times 170 \mathrm{~mm} \times 5 \mathrm{~mm}$. The lengths of the beam and the column of these connections are $1400 \mathrm{~mm}$ and $1450 \mathrm{~mm}$, respectively, and the beam-column section stiffness ratio is 0.32 . According to the American code [25], the structural size of the reinforcing rib should meet the following requirements: the length of $a=(0.6-0.7) h_{b}$, which is the beam section height, and the width of $b=(0.45-0.55) a, a^{\prime} \approx 0.2 a, b^{\prime} \approx 0.2 b$, and the thickness is $t_{s} \geqslant 1.5 t_{f}$, which is the beam flange thickness. The details of the beam and column are shown in Table 1 . According to the above rules, the length $a=160 \mathrm{~mm}$, the width $\mathrm{b}=80 \mathrm{~mm}, a^{\prime}=35 \mathrm{~mm}, b^{\prime}=20 \mathrm{~mm}$, and the thickness $t_{s}=2 \times 6 \mathrm{~mm}$, are used in this study. The details of these two specimens and the model parameters are shown in Fig. 1.

Table 1

Parameters of Specimens

\begin{tabular}{cccccccc}
\hline \multirow{2}{*}{$\begin{array}{c}\text { Specimen } \\
\text { number }\end{array}$} & Beam section & Column section & \multicolumn{4}{c}{ Parameters of ribs (mm) } \\
\cline { 3 - 7 } & $(\mathrm{mm})$ & $(\mathrm{mm})$ & $a$ & $b$ & $a$ & $b^{\prime}$ & $t_{s}$ \\
\hline NBN & $\mathrm{HN}$ & $\mathrm{HW}$ & $/$ & $/$ & $/$ & $/$ & $/$ \\
& $248 \times 24 \times 5 \times 8$ & $250 \times 250 \times 9 \times 14$ & & & & & \\
RRN & $\mathrm{HN}$ & $\mathrm{HW}$ & & & & & \\
& $248 \times 124 \times 5 \times 8$ & $250 \times 250 \times 9 \times 14$ & & & & & \\
\hline
\end{tabular}



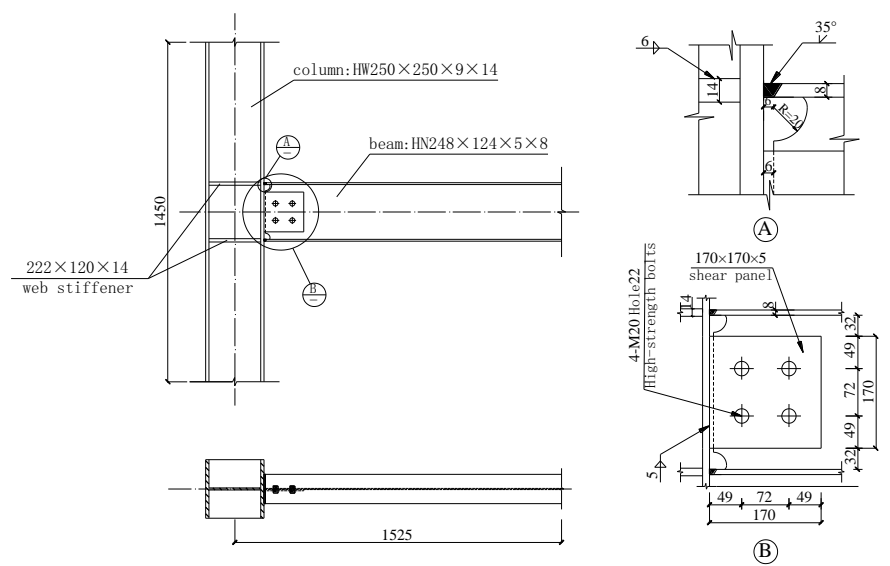

(a) Normal beam-column connection (NBN)
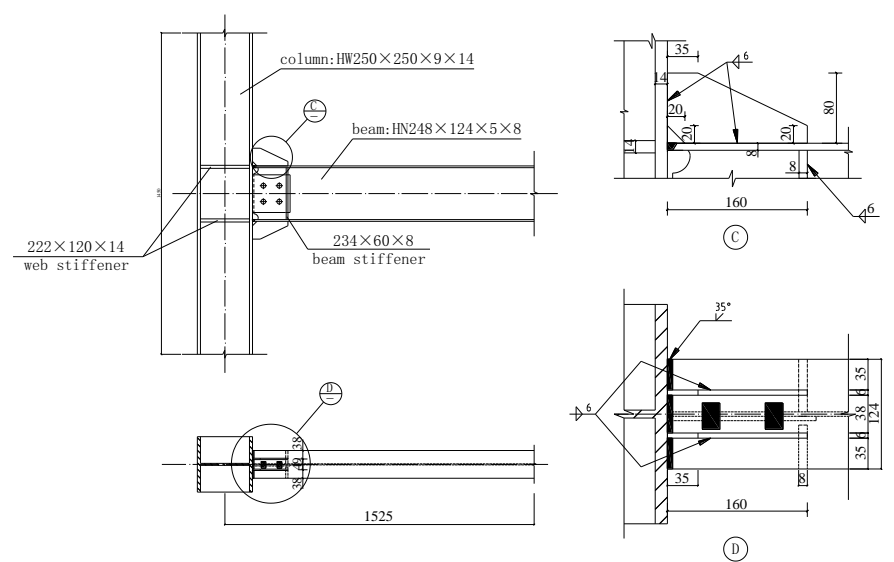

(b) Double-ribbed reinforced beam-column connection (RRN)

Fig. 1 Details of specimens

\subsection{Mechanical properties of the material}

Five plate samples (thicknesses of $5 \mathrm{~mm}, 6 \mathrm{~mm}, 8 \mathrm{~mm}, 9 \mathrm{~mm}$ and $14 \mathrm{~mm}$ ) are taken from the shear plate, ribs, webs, and flanges of the beam and column in accordance with relevant codes [26,27], and three groups of tensile testing specimens are prepared for each sample type. The detailed dimensions of the samples are shown in Fig. 2(a). The samples are subjected to uniaxial tensile loads by a WDW-300 microcomputer controlled electronic universal testing machine (the test setup and the failure mode of the specimens are shown in Fig. 2(b)).The Young's modulus, yield strength, tensile strength, and elongation are obtained. Table 2 shows the tested material properties, and the deviations between the material performance data and the theoretical values of the Q345B plate.

Table 2

Material properties of the plate samples

\begin{tabular}{cccccc}
\hline $\begin{array}{c}\text { Specimen } \\
\text { No. }\end{array}$ & $\begin{array}{c}\text { Section } \\
\text { area }\end{array}$ & $\begin{array}{c}\text { Yield } \\
\text { strength } \\
\mathrm{A}_{1} / \mathrm{mm} 2\end{array}$ & $\begin{array}{c}\text { Tensile } \\
\text { strength } \\
f_{y 1} / \mathrm{MPa}\end{array}$ & $\begin{array}{c}\text { Elastic } \\
\text { modulus }\end{array}$ & $\begin{array}{c}\text { Elongation } \\
f_{u 1} / \mathrm{MPa}\end{array}$ \\
\hline A-1 & 72.81 & 358.85 & 590.53 & 202860 & 9.82 \\
A-2 & 72.77 & 339.41 & 582.59 & 203325 & 8.64 \\
A-3 & 73.85 & 360.52 & 595.39 & 206894 & 9.66 \\
B-1 & 83.01 & 340.84 & 572.26 & 205687 & 10.13 \\
B-2 & 86.45 & 380.26 & 606.23 & 203346 & 9.20 \\
B-3 & 87.35 & 366.22 & 590.16 & 198892 & 9.92 \\
C-1 & 118.88 & 342.15 & 585.69 & 197961 & 11.58 \\
C-2 & 117.36 & 378.94 & 608.57 & 201238 & 11.12 \\
C-3 & 116.38 & 362.59 & 585.58 & 205897 & 11.88 \\
D-1 & 128.52 & 353.68 & 588.41 & 206502 & 11.90 \\
D-2 & 131.47 & 362.15 & 589.63 & 198592 & 11.62
\end{tabular}

\begin{tabular}{cccccc} 
D-3 & 130.70 & 349.86 & 580.22 & 198950 & 12.14 \\
E-1 & 206.88 & 351.63 & 573.86 & 206253 & 15.56 \\
E-2 & 205.53 & 364.12 & 585.58 & 205682 & 15.81 \\
E-3 & 206.31 & 372.59 & 600.26 & 203960 & 15.06 \\
\multicolumn{2}{c}{ Average value } & 358.92 & 589 & 203069 & 11.60 \\
Deviation from theoretic & 4.04 & 6.13 & -0.94 & / \\
\multicolumn{2}{c}{ value (\%) }
\end{tabular}

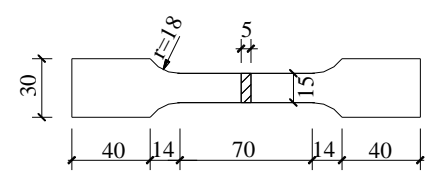

5 mm (A-1、A-2、A-3)

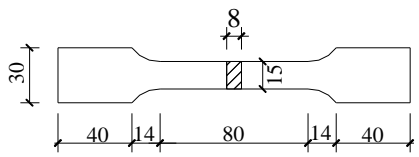

$8 \mathrm{~mm}(\mathrm{C}-1 、 \mathrm{C}-2 、 \mathrm{C}-3)$

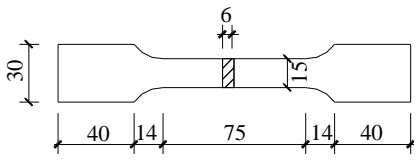

$6 \mathrm{~mm}(\mathrm{~B}-1 、 \mathrm{~B}-2 、 \mathrm{~B}-3)$

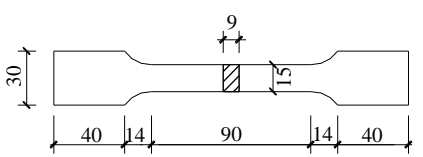

$9 \mathrm{~mm}(\mathrm{D}-1 、 \mathrm{D}-2 、 \mathrm{D}-3)$ (a) Plate samples
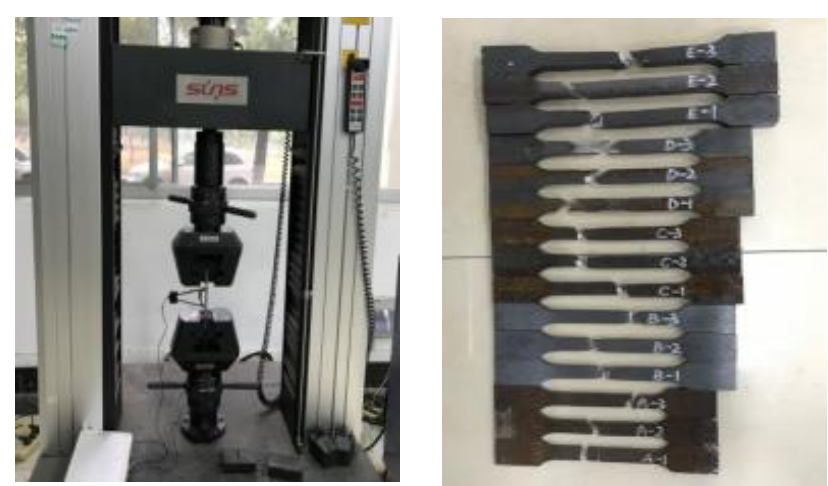

(b) Test setup and failure mode

Fig. 2 Details of plate samples

\subsection{Instrumentation}

The displacement is measured with the YHD-50 high-precision displacement meters, whereas the strain acquisition is performed with a DH3816N static strain test system. The following measurements are acquired: (1) the load-displacement curve, (2) the strain in the upper/lower flanges and the web of beam, (3) the strain in two reinforced ribs, (4) the relative displacement of two diagonal points in the node domain, (5) the horizontal displacement of the flange at the beam end and the vertical displacement of the column corner. The locations of the strain gauges and displacement meters are shown in Fig. 3.

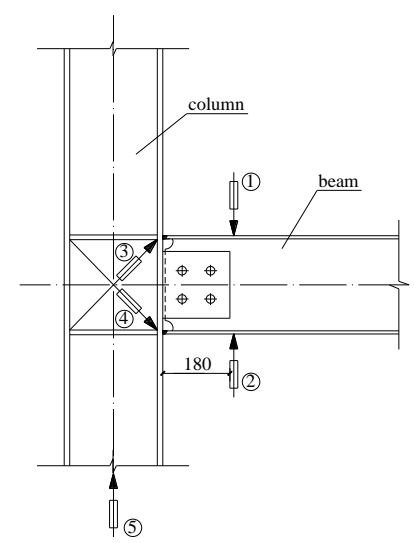

(a) Arrangement of displacement meter
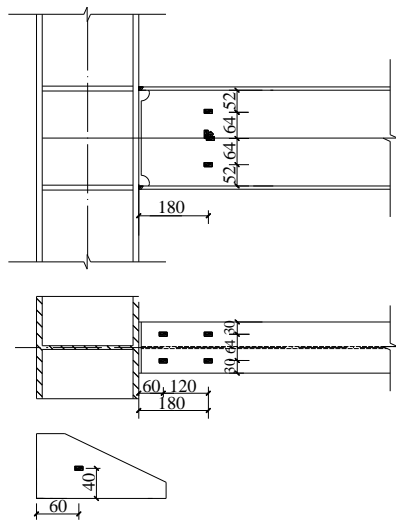

(b) Strain gauge arrangement
Fig. 3 Instrumentation (Unit: $\mathrm{mm}$ ) 


\subsection{Loading protocol}

According to the Chinese code [28], when the resistance of the connection reaches the peak value and then drops to $85 \%$ of the ultimate load, the failure state is reached. When the maximum load reaches the ultimate capacity of the loading equipment, the loading should be stopped. The loading method is shown in Fig. 4 and Table 3.

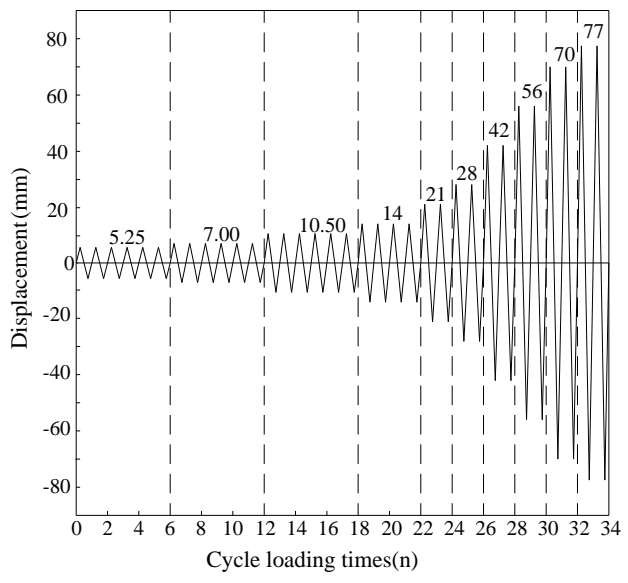

Fig. 4 Loading method

Table 3

Loading scheme

\begin{tabular}{cccc}
\hline $\begin{array}{c}\text { Loading } \\
\text { level }\end{array}$ & $\begin{array}{c}\text { Displacement } \\
\text { amplitude }(\mathrm{mm})\end{array}$ & $\begin{array}{c}\text { Interlayer displacement } \\
\text { angle(rad) }\end{array}$ & Loading step \\
\hline 1 & 5.25 & 0.00375 & 6 \\
2 & 7.00 & 0.00500 & 6 \\
3 & 10.50 & 0.00750 & 6 \\
4 & 14.00 & 0.01000 & 4 \\
5 & 21.00 & 0.01500 & 2 \\
6 & 28.00 & 0.02000 & 2 \\
7 & 42.00 & 0.03000 & 2 \\
8 & 56.00 & 0.04000 & 2 \\
10 & 70.00 & 0.05000 & 2 \\
\hline
\end{tabular}

\subsection{Experimental setup}

The column is horizontally placed on the hinged supports with a height of $60 \mathrm{~mm}$, which is reliably connected to the rigid ground by anchors. A thrust collar is used to prevent horizontal slip so that the articulated boundary conditions of the column are ensured. The tensile or compressive loads are applied by a 50T-MTS hydraulic servo actuator, which is horizontally fixed on the reaction wall. Moreover, the computer simultaneously collects load, displacement, and strain data. The experimental setup is shown in Fig. 5.

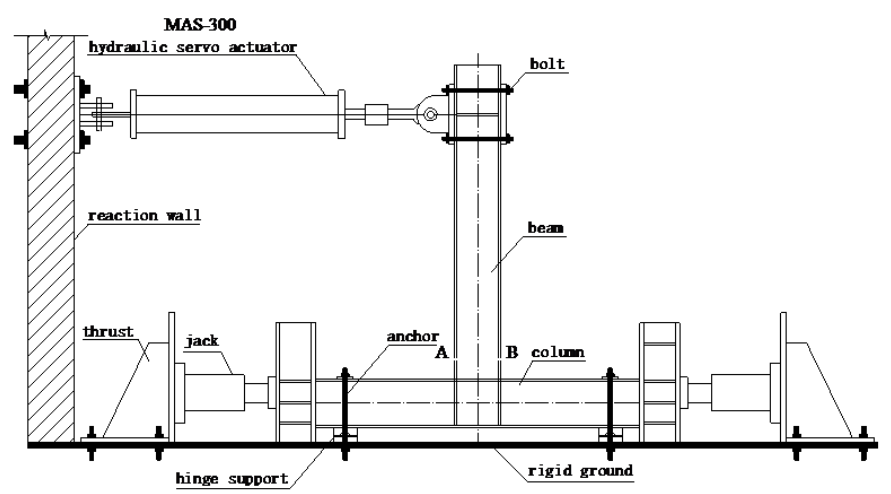

(a) Schematic diagram

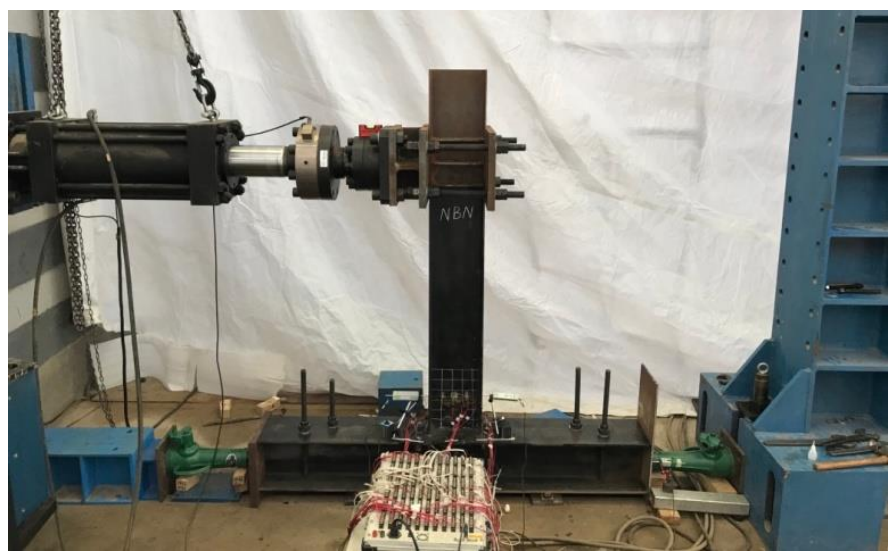

(b) Actual loading device

Fig. 5 Testing setup

\section{Numerical simulation}

The normal beam-column connection (NBN) and the double-ribbed reinforced beam-column connection are analyzed by ABAQUS software [29, 30].

\subsection{Constitutive model of the materials}

The constitutive relations of the Q345B steel, E5015 weld, and bolts (all three materials adopt three-fold line models (Song [31])) are shown in Fig. 6. The material parameters of the Q345B steel, E5015 weld and bolts are listed in Table 4, where $E$ is the Young's modulus, $f_{y}$ is the yield strength, $\varepsilon_{y}$ is the yield strain corresponding to the yield strength, $f_{u}$ is the ultimate strength, and $\varepsilon_{u}$ is the ultimate strain corresponding to the ultimate strength. The parameters of the connections, such as the geometric nonlinearity, material nonlinearity and the Bauschinger effect [32], and the effects of welding defects are taken into consideration, while the residual stresses caused by welding are not considered.

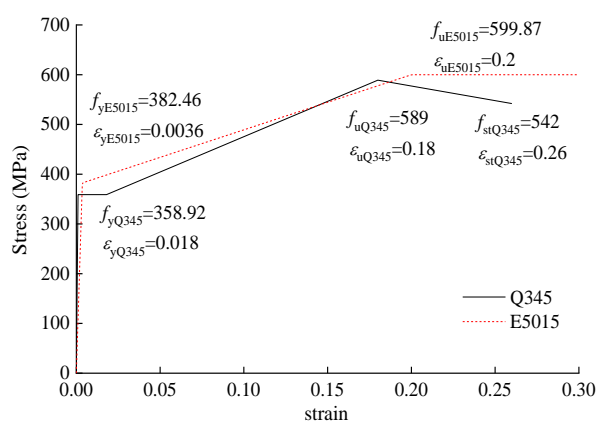

(a) Steel and weld

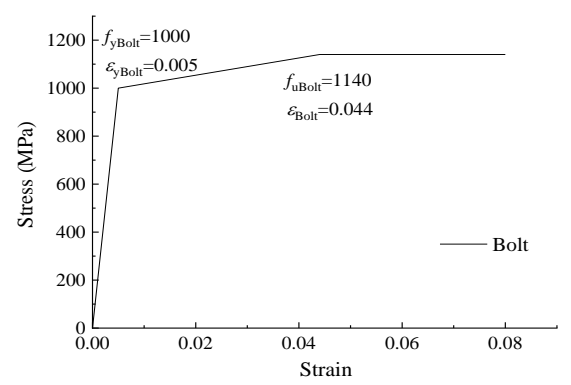

(b) Bolt

Fig. 6 Material constitutive model 
Table 4

Constitutive parameters of the materials

\begin{tabular}{ccccccc}
\hline Material & $E(\mathrm{GPa})$ & $f_{y}(\mathrm{MPa})$ & $\varepsilon_{y}$ & $f_{u}(\mathrm{MPa})$ & $\varepsilon_{u}$ & $v$ \\
\hline Q345B & 203.069 & 358.92 & 0.0018 & 589.0 & 0.18 & 0.3 \\
E5015 & 204.720 & 382.46 & 0.0036 & 599.9 & 0.20 & 0.3 \\
Bolt & 206.00 & 1000.0 & 0.0050 & 1140.0 & 0.044 & 0.3 \\
\hline
\end{tabular}

\subsection{Mesh and boundary conditions}

The solid eight-node hexahedral linear reduced integral element (C3D8R), which has the advantages of high accuracy, low computational cost, and better ability to withstand buckling deformation [33], is selected to mesh the beam, column, shear plate, bolts, ribs, column stiffeners, and welds. For most parts of the beam and the column, the mesh size is approximately $30 \mathrm{~mm}$. The mesh size at the beam-column connection and the beam within a length of $180 \mathrm{~mm}$ from the beam end, rib plate, shear plate, and bolts is approximately $10 \mathrm{~mm}$, and the mesh size at the welds is approximately $2 \mathrm{~mm}$. The whole structure is divided into 15,916 elements, and the FE model is shown in Fig. 7. Face-to-face contact is adopted between the bolt and steel. The Coulomb friction "penalty" function is adopted for the tangent friction of the contact surfaces, and the friction coefficient is 0.3 (no friction is set between the screw and wall hole).In the normal direction, a "hard" contact is used. In the load interface, the displacement and rotation angle of the two ends of the column in the $\mathrm{X}, \mathrm{Y}$, and $\mathrm{Z}$ directions are constrained first, and the displacement is controlled at the coupling point. The loading system is consistent with that of the test.

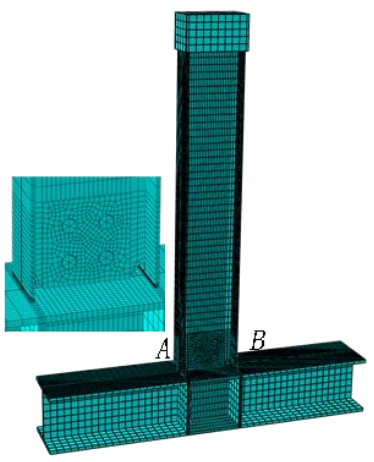

(a) NBN

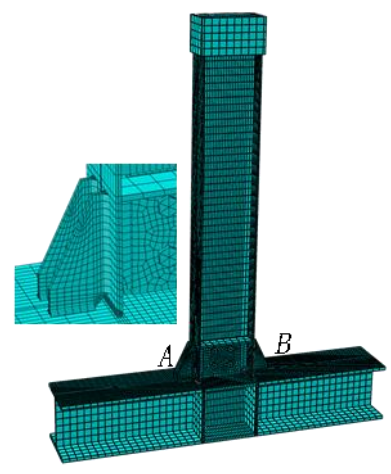

(b) RRN
Fig. 7 Finite element models

\subsection{Hysteretic behavior}

\subsubsection{Specimen deformation}

(1) Normal beam-column connection (NBN)

Fig. 8 presents the deformed diagram of the test and numerical simulation of the common connections $(\mathrm{NBN})$ at different loading levels. The highest value is set to $600 \mathrm{MPa}$ since the average experimental ultimate tensile strength of Q345B steel is $589 \mathrm{MPa}$, and the maximum experimental value is $608 \mathrm{MPa}$ from Table 2. If the stress of any part exceeds the highest value, these parts turn gray. Then, they will be regarded as failed or damaged. The results show that the numerical results and test results for the plastic hinge position and the deformation are basically the same. The whole connection is still in the elastic stage at the fourth loading level, and the stress at the beam end is the largest from the simulation results. The test and numerical results show that the beam experiences severe buckling at $80 \mathrm{~mm}$, and a plastic hinge begins to appear at the seventh loading level, but the deformation in the finite element analysis is more obvious than that in the actual test because the whole analysis process is ideal. The welds of sides A and B are damaged to varying degrees at the ninth loading level in the theoretical results. However, damage to the weld occurs at the eighth level, and the damage is severe.

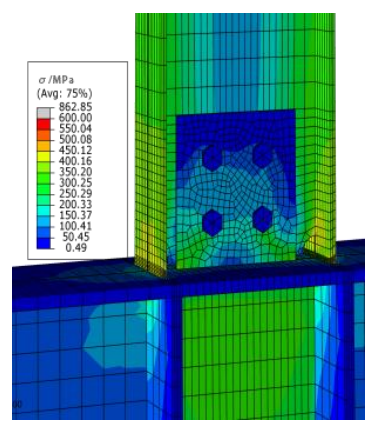

(a) Stress cloud diagram at level 4 loading

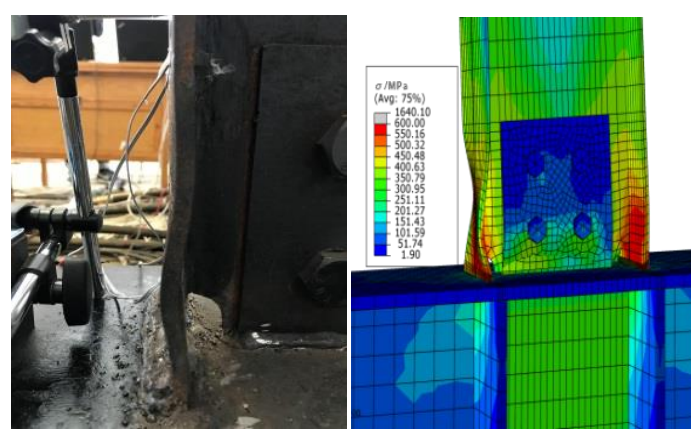

(b) Plastic hinge change at level 7 loading

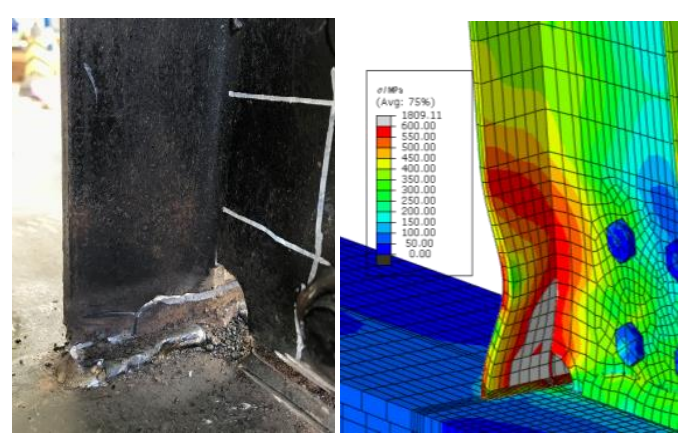

(c) Failure of A-side flange at level 9 loading

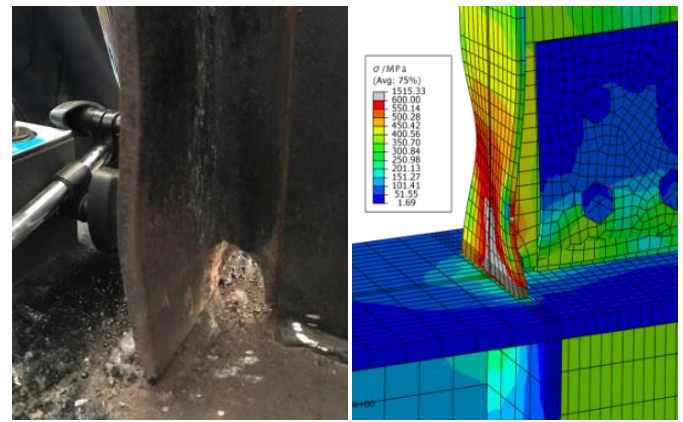

(d) Failure of B-side flange at level 9 loading

Fig. 8 Comparison of deformation of specimen NBN

(2) Double-ribbed reinforced beam-column connection (RRN)

In the same way, the deformed diagram for the test and numerical simulation of the double-ribbed reinforced connections (RRN) at different loading levels are presented in Fig. 9. The results show that both the numerical and tested results at the plastic hinge position and the deformation size are not the same as that of the NBN because of the existence of strengthened ribs. The whole connection is also in the elastic range at the fourth loading level, but the largest stress from the simulation results is at the ribs and beam flanges near the ends of the ribs and the strengthened web plate. The test and numerical results showed that the beams buckled slightly in the two above parts and the weld that connects the beam and the column at the ninth loading level. The welds of the rib of side A and that of the beam flange of side B crack at the tenth loading level during the structural test, but the damage of side A and side B is symmetrical. The damage of the welds of side 
A and side B occurs at different parts during the test because the quality of the welds is inconsistent due to manual welding.

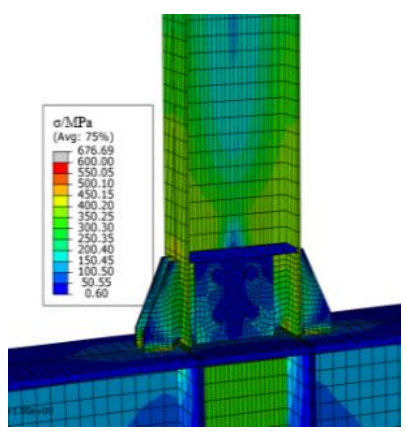

(a) Stress cloud diagram at 4 level loading

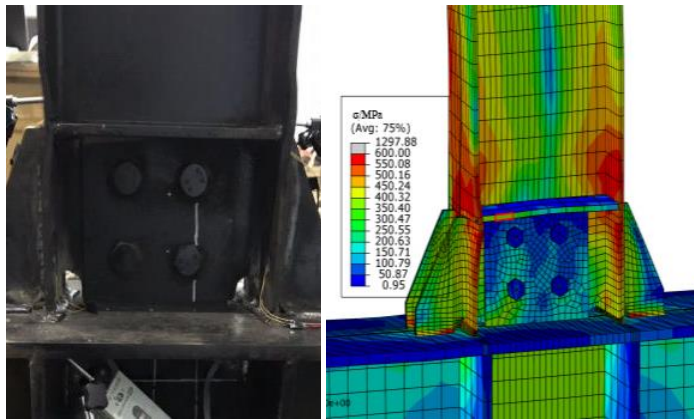

(b) Plastic hinge change at 8 level loading

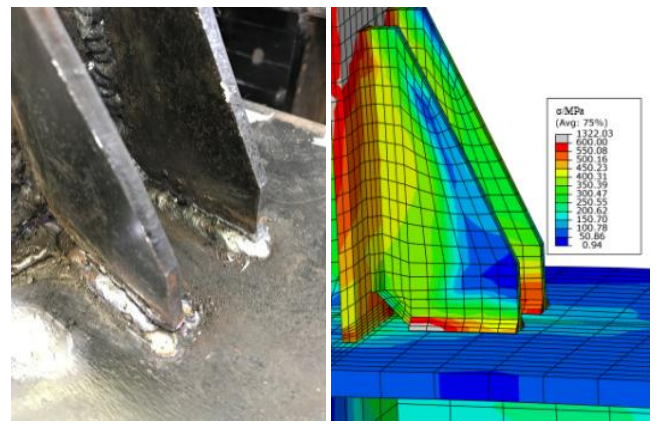

(c) Failure of A-side rib at 9 level loading

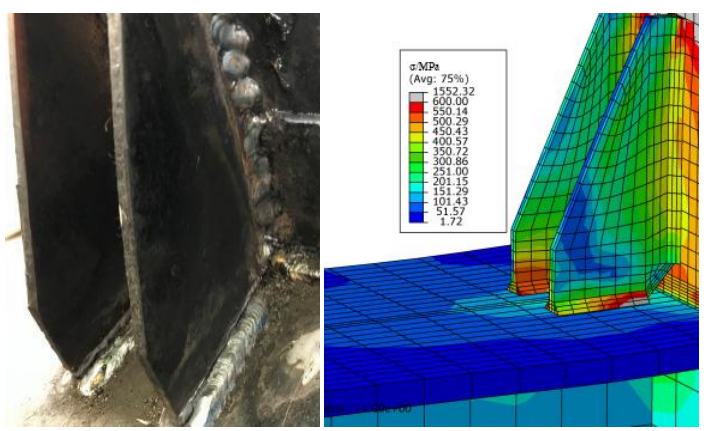

(d) Failure of B-side rib at 9 level loading

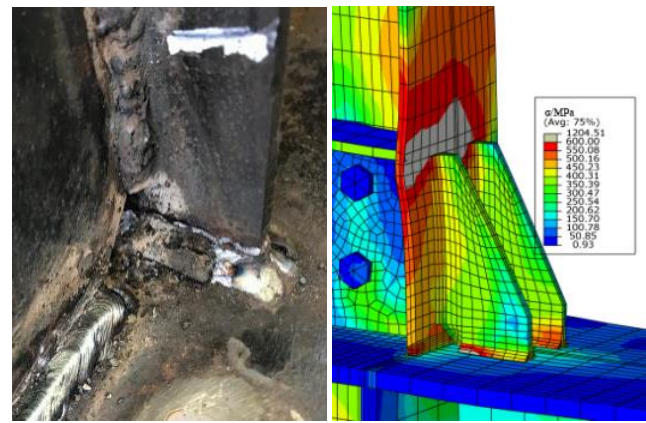

(e) Failure of A-side flange at 10 level loading
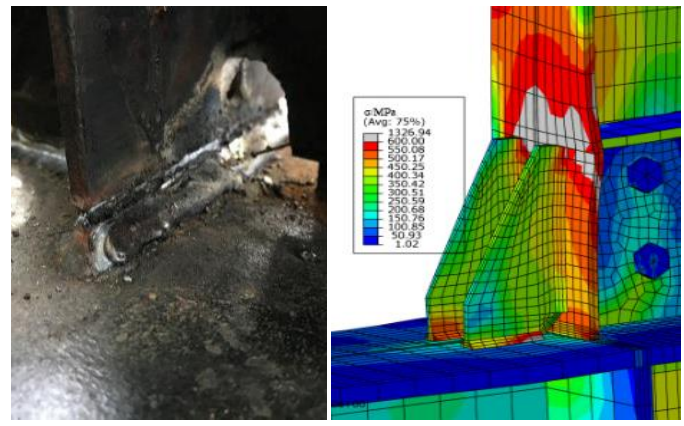

(f) Failure of B-side flange at 10 level loading

Fig. 9 Comparison of deformation of specimen RRN

\subsubsection{Hysteretic curve}

Fig. 10 shows the comparison of the hysteresis curves obtained by the test and the numerical results. All of the curves exhibit spindle shapes. However, the stress values from the test are slightly smaller than those from the FE results; moreover, rheostriction is observed in the middle of the test curves. It is determined that there is a small level of slippage during the test. The results also show that both hysteresis curves obtained from the test and the finite element calculation are basically consistent at the initial loading stage. After reaching the peak load, the hysteresis curves of the specimen in the test are not full enough because specimens had defects in the welds, and there were some unstable factors, such as the stress concentration caused by the weld processing errors, and uneven material properties in the test. Comparing the hysteresis curves of the two connections proves that the double-ribbed reinforced beam-column connection has better seismic performance than the other connection because it is fuller and exhibits a higher bearing capacity.

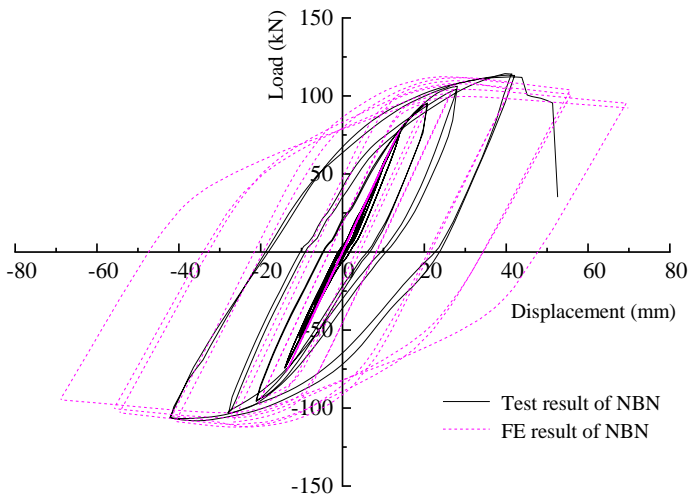

(a) $\mathrm{NBN}$

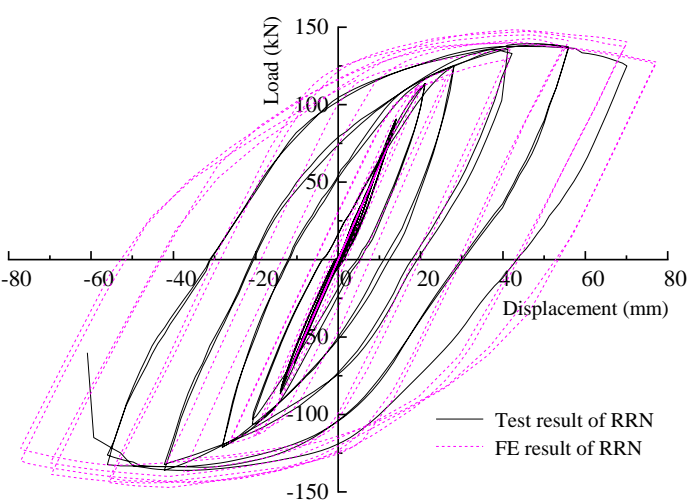

(b) RRN

Fig. 10 Comparison of hysteretic curves

\subsubsection{Skeleton curve and stiffness degradation curves}

The skeleton curve can reflect the relationship between the strength and deformation of a component. Fig. 11 presents four skeleton curves of the NBN and RRN from the tests and numerical simulations. This figure shows that the skeleton curves of each specimen are linear before yielding, while they are nonlinear after yielding. Besides, the skeleton curves of the experiment and 
simulation basically coincide with each other before yielding. Upon reaching the ultimate load, the decline slope of the RRN curves is less than that of the NBN curves, which indicates that there is a larger plastic deformation at the strength node, and the plasticity of the steel beam-column connection always plays an important role. However, after exceeding the peak point, the test and simulation curves begin to separate. The decrease in the skeleton curve of the simulation is relatively smaller than that of the test because the material of the finite element model is relatively ideal. Meanwhile, it could be concluded from these curves that the double-ribbed reinforced beam-column connection has a higher bearing capacity than the other connections.

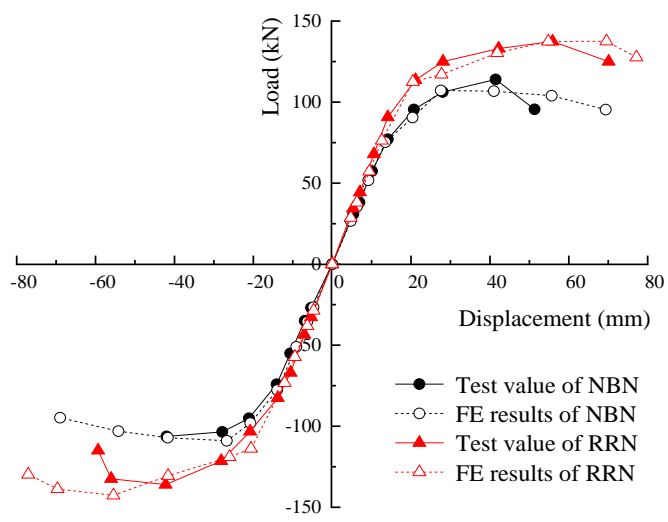

Fig. 11 Comparison of skeleton curves

Additionally, stiffness degradation refers to the phenomenon that the stiffness of the secant at each point on the skeleton curve gradually decreases after the specimen enters the plastic stage. The degree of degradation can be measured by the stiffness degradation coefficient $\beta$, which refers to the stiffness of the loaded secant position and the stiffness at the initial elastic stage ratio. According to the coordinates of each point on the skeleton curve, the coefficient of stiffness degradation corresponding to each stage of loading is calculated and drawn into a curve, as shown in Fig. 12. Before reaching the fifth loading level, the stiffness of the two connections barely decreases. After entering the yield stage, the test values of the NBN are highly coincident with those of the simulation, but the test results of the RRN are generally lower than those of the simulation. The development of the plastic hinge and failure mode of the numerical simulation and test of the NBN are consistent, as seen from the comparison with the displacement in the whole loading process. However, after the plastic hinges appear at the beam end of the RRN, with the increase in the loading grade, the buckling of the beam flange in the test or simulation is intensified in the same position, but the change in the test is not obvious.

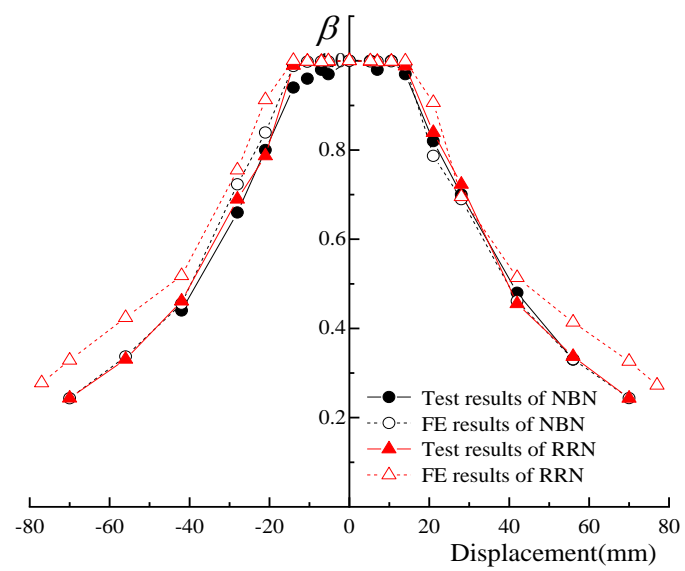

Fig. 12 Comparison of stiffness degradation curves

\subsubsection{Ductility and energy dissipation coefficient}

The ductility is an important index for evaluating the seismic resistance of connection specimens, which is defined as the ratio of the ultimate displacement $\Delta_{u}$ to the yield displacement $\Delta_{y}$. The ductility coefficients of the NBN and RRN are shown in Table 5. In terms of $\mu$, the positive and negative ductility coefficients of the same specimen have little difference, but the average value of the ductility coefficient of the RRN is $38.3 \%$, which is higher than that of the NBN. Meanwhile, the ductility coefficients of the RRN are larger than those of the NBN. This means that reinforcing the beam with ribs can significantly improve the ductility of the beam-column connection.

Table 5

Load and displacement at characteristic points and ductility factor

\begin{tabular}{cccccccc}
\hline $\begin{array}{c}\text { Speci- } \\
\text { men }\end{array}$ & $\begin{array}{c}\text { Force } \\
\text { direction }\end{array}$ & $\begin{array}{c}D_{\mathrm{y}} \\
(\mathrm{mm})\end{array}$ & $\begin{array}{c}P_{\mathrm{y}} \\
(\mathrm{kN})\end{array}$ & $\begin{array}{c}D_{\mathrm{u}} \\
(\mathrm{mm})\end{array}$ & $\begin{array}{c}P_{\mathrm{u}} \\
(\mathrm{kN})\end{array}$ & $\mu$ & $\bar{\mu}$ \\
\hline \multirow{2}{*}{ NBN } & Positive & 20.64 & 88.56 & 51.33 & 114.00 & 2.48 & \multirow{2}{*}{2.30} \\
& negative & 19.85 & 89.98 & 42.02 & 106.30 & 2.12 & \\
\multirow{2}{*}{ RRN } & Positive & 20.66 & 112.20 & 70.10 & 137.42 & 3.39 & \multirow{2}{*}{3.18} \\
& negative & 20.06 & 100.62 & 59.36 & 136.15 & 2.96 & \\
\hline
\end{tabular}

In general, the equivalent adhesive damper coefficient $h_{e}$ [21] can measure the energy dissipation capacity of a beam-column connection Comparing the equivalent adhesive damping coefficients of the two types of beam-column connections (which are shown in Table 6), these values for the RRN are still larger than that for the NBN, which shows that the reinforced ribs of the beam have some effect on the value of $E_{h}$ in each model, and the reinforcing ribs will increase the energy dissipation coefficient of the connections.

Table 6

Comparison of equivalent adhesive damper coefficients

\begin{tabular}{cccc}
\hline Specimen & Test value & Theoretical value & Error/\% \\
\hline NBN & 0.290 & 0.322 & 11.03 \\
RRN & 0.345 & 0.368 & 6.67 \\
\hline
\end{tabular}

\subsubsection{Damage curve}

Corresponding to the hysteretic curves of both beam-column connections, the damage curves are fitted by a power function, which is shown in Fig. 13, where the damage modulus is calculated by the energy model [34], and the curves of both specimens are highly consistent with the damage value. The cumulative plastic damage values of both connections are relatively large because the simulation displacement results are large. Besides, the slope of these curves has gone through the same process from small to large, which proves that the damage degradation of both connections is accelerated. The final damage value of the simulation of the NBN is higher than that of the test, and the difference between the final damage value and the fitting formula of the RRN is small. Moreover, the final damage value of the RRN is still higher than that of the NBN, and the energy dissipation time of the RRN is longer than that of the NBN. This result is consistent with the conclusion from the experimental results.

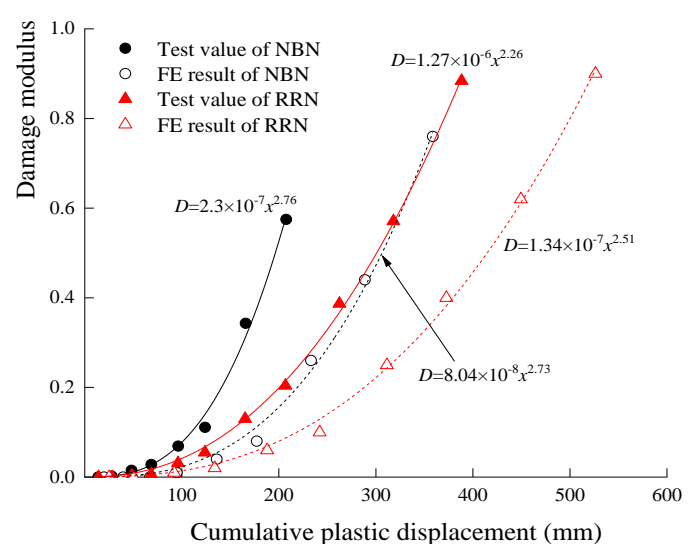

Fig. 13 Comparison of fitting curves of damage degradation

From the above seismic performance analysis, it is recommended that the double-ribbed reinforced beam-column connection is adopted for a steel frame in practical engineering applications, but the optimal range of the ribs cannot be obtained by only one length.

\section{Parameter analysis with reinforced ribs}

4.1. FE model analysis 
From the evolution of fracture theory, if double-ribbed reinforced beam-column connections are to fully realize the purpose of fracture resistance under earthquake loads, it is also necessary to study the brittle fracture of steel connections with expanded flanges. According to the experimental and simulated failure modes of the RRN, the flange weld between the beam and column and the plastic hinge belong to the key failure zone. Based on the results of the above test and numerical simulation, the parameters of the finite element model of the RRN are consistent with those of the above specimens. To distinguish the influence of ribs of different sizes on the fracture performance of these connections, the ranges of the parameters of the reinforced ribs of the RRN are expanded as length $l_{a}=(0.55 \sim 0.75) h_{\mathrm{b}}$, width $b=(0.4 \sim 0.6) a$, thickness $t_{s}=(1.4 \sim 1.8) t_{f}, \mathrm{a}^{\prime}=35 \mathrm{~mm}$ and $b^{\prime}=20 \mathrm{~mm}$. The dimensions and key analysis parts of the ribbed plate are shown in Fig. 14. These models are divided into three group models (RRN-A, RRN-B, and RRN-C) in accordance with the three indexes of the rib length, width, and thickness. Every index of the rib in each group of models has five different parameters, which are shown in Table 7, Table 8, and Table 9.

Table 7

Parameters of ribbed plate of RRN-A group model

\begin{tabular}{ccccccc}
\hline Model number & $a(\mathrm{~mm})$ & $a / h_{\mathrm{b}}$ & $b(\mathrm{~mm})$ & $b / a$ & $t_{\mathrm{s}}(\mathrm{mm})$ & $t_{\mathrm{s}} / t_{\mathrm{f}}$ \\
\hline RRN-A1 & 137.5 & 0.55 & 69 & 0.5 & 12 & 1.5 \\
RRN-A2 & 150 & 0.6 & 75 & 0.5 & 12 & 1.5 \\
RRN-A3 & 162.5 & 0.65 & 81 & 0.5 & 12 & 1.5 \\
RRN-A4 & 175 & 0.7 & 88 & 0.5 & 12 & 1.5 \\
RRN-A5 & 187.5 & 0.75 & 94 & 0.5 & 12 & 1.5 \\
\hline
\end{tabular}

Table 8

Parameters of ribbed plate of RRN-B group model

\begin{tabular}{ccccccc}
\hline Model number & $a(\mathrm{~mm})$ & $a / h_{\mathrm{b}}$ & $b(\mathrm{~mm})$ & $b / a$ & $t_{\mathrm{s}}(\mathrm{mm})$ & $t_{\mathrm{s}} / t_{\mathrm{f}}$ \\
\hline RRN-B1 & 160 & 0.645 & 64 & 0.4 & 12 & 1.5 \\
RRN-B2 & 160 & 0.645 & 72 & 0.45 & 12 & 1.5 \\
RRN-B3 & 160 & 0.645 & 80 & 0.5 & 12 & 1.5 \\
RRN-B4 & 160 & 0.645 & 88 & 0.55 & 12 & 1.5 \\
RRN-B5 & 160 & 0.645 & 96 & 0.6 & 12 & 1.5 \\
\hline
\end{tabular}

Table 9

Parameters of ribbed plate of RRN-C group model

\begin{tabular}{ccccccc}
\hline Model number & $a(\mathrm{~mm})$ & $a / h_{\mathrm{b}}$ & $b(\mathrm{~mm})$ & $b / a$ & $t_{\mathrm{s}}(\mathrm{mm})$ & $t_{\mathrm{s}} / t_{\mathrm{f}}$ \\
\hline RRN-C1 & 160 & 0.645 & 80 & 0.5 & 11.2 & 1.4 \\
RRN-C2 & 160 & 0.645 & 80 & 0.5 & 12 & 1.5 \\
RRN-C3 & 160 & 0.645 & 80 & 0.5 & 12.8 & 1.6 \\
RRN-C4 & 160 & 0.645 & 80 & 0.5 & 13.6 & 1.7 \\
RRN-C5 & 160 & 0.645 & 80 & 0.5 & 14.4 & 1.8 \\
\hline
\end{tabular}

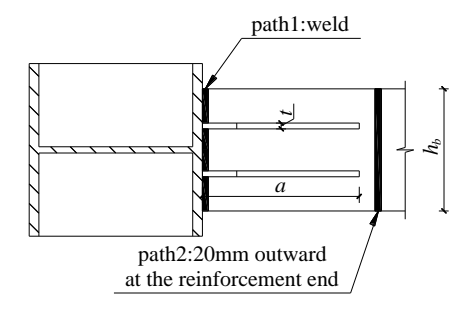

(a) Critical path

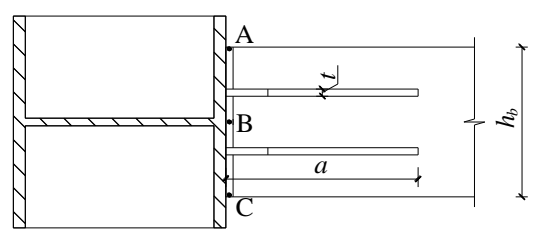

(b) Key point

\subsection{Fracture analysis indexes}

Using the indexes (stress triaxiality ratio $\left(R_{\sigma}\right)$, plastic equivalent strain index (P.I.), and cracking index (R.I.)), the possibility of brittle fracture of the RRN is analyzed, and the fracture characteristics of these connections are studied and evaluated. Furthermore, the influence of ribs of different sizes on the fracture performance of these connections is comprehensively analyzed.

The stress triaxiality ratio can effectively reflect the plastic deformation and stress concentration in the material (Schafer B. W. et al. [35]). The larger the $\mathrm{R} \sigma$ value is, the larger the volumetric deformation. The greater the stress concentration, the more elastic strain energy is released, and the easier it is for cracks to occur. The specific calculation is as follows:

$R_{\sigma}=\frac{\sqrt{2}\left(\sigma_{1}+\sigma_{2}+\sigma_{3}\right)}{3 \sqrt{\left(\sigma_{1}-\sigma_{2}\right)^{2}+\left(\sigma_{2}-\sigma_{3}\right)^{2}+\left(\sigma_{3}-\sigma_{1}\right)^{2}}}$

where $\sigma_{1}, \sigma_{2}$, and $\sigma_{3}$ are the principal stresses.

EI-Tawil [36] proposed the equivalent plastic strain index, which is equal to the ratio between the equivalent plastic strain and the yield strain. The equivalent plastic strain index can reflect the local ductility and fracture tendency of the material. The larger the value of P.I. is, the greater the plastic deformation at that point, and the greater the possibility of ductile cracking of the material, which is defined as follows:

$P I=\frac{\sqrt{\frac{2}{3} \varepsilon_{i j} \varepsilon_{i j}}}{\varepsilon_{y}}$

where $\varepsilon_{y}$ is the yield strain at the calculation point and $\varepsilon_{i j}$ is the equivalent plastic strain component.

Haneock [37] and Mao [39] proposed using the stress triaxiality ratio Ro and the equivalent plastic strain index P.I. to define the cracking index R.I. when studying the brittle fracture of metal materials. The cracking index is equal to the ratio between the average stress and the equivalent stress. The higher the R.I. value is, the greater the possibility of cracking, and the larger the joint damage. The calculation formula is as follows:

$$
R I=\frac{P I}{\exp \left[-3\left(\sigma_{1}+\sigma_{2}+\sigma_{3}\right) / 4 \sigma_{e}\right]}
$$

where $\sigma_{e}$ is the von Mises stress.

\subsection{Influence of $l_{a}$}

The elastic-plastic fracture indexes $\left(R_{\sigma}, P I\right.$, and R.I.) of path 1 , path 2 , and three key points of RRN-A derived from ABAQUS are shown in Figs. 15-17, respectively.

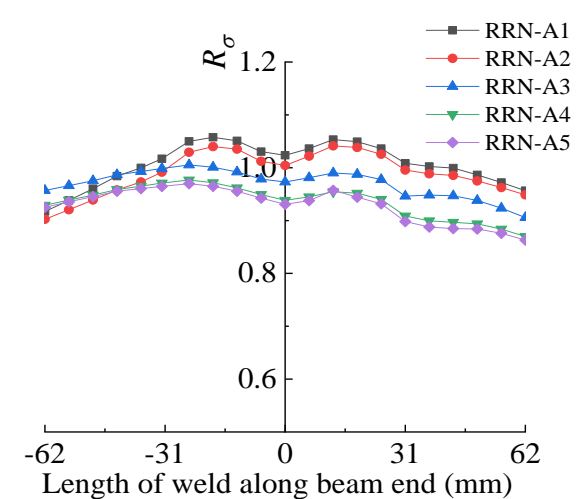

(a) Stress triaxiality ratio

Fig. 14 Key paths and key point 


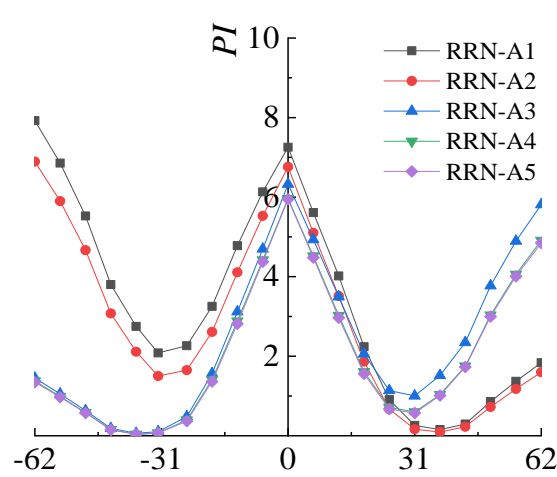

Length of weld along beam end $(\mathrm{mm})$

(b) Equivalent plastic strain index

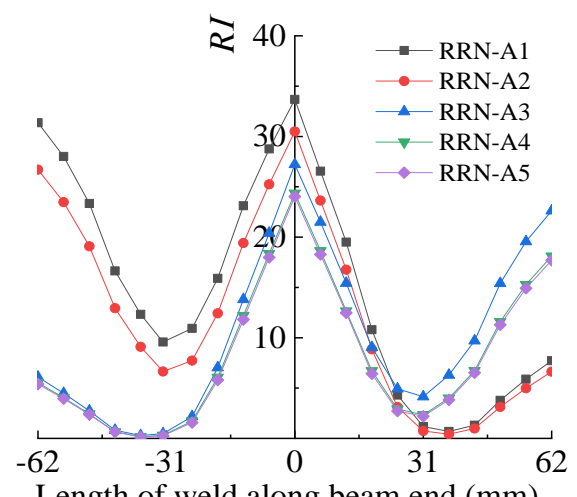

Length of weld along beam end ( $\mathrm{mm})$

(c) Cracking index

Fig. 15 Fracture assessment parameters in path 1 of the RRN-A

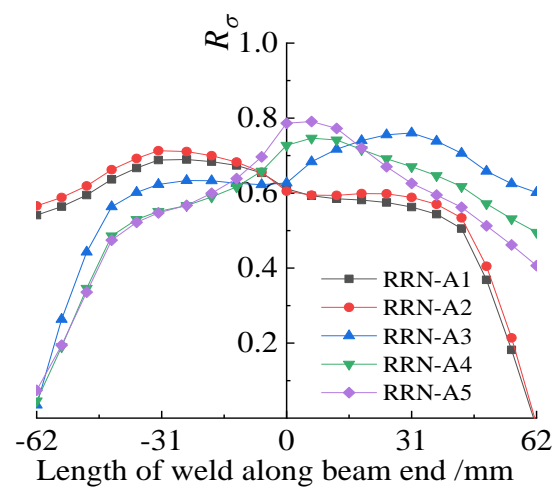

(a) Stress triaxiality ratio

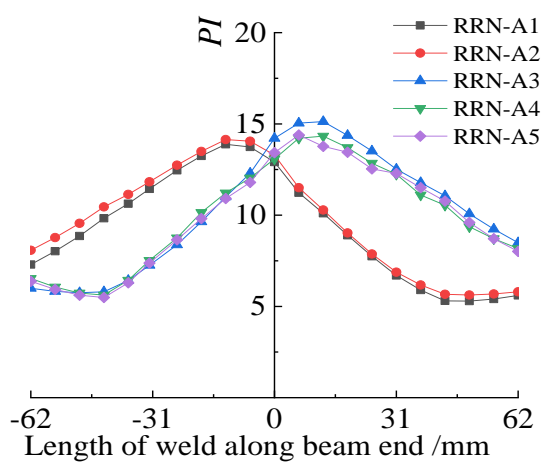

(b) Equivalent plastic strain index

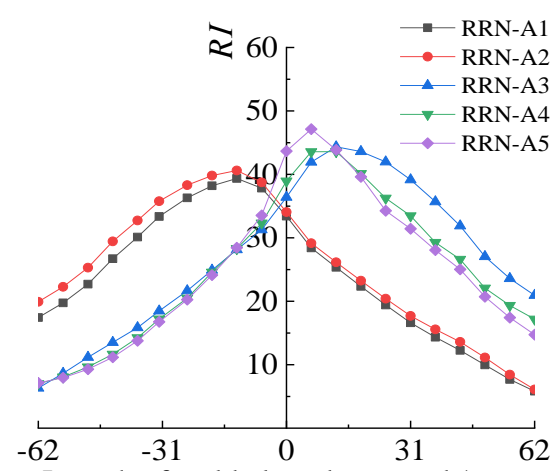

Length of weld along beam end $/ \mathrm{mm}$

(c) Cracking index

Fig. 16 Fracture assessment parameters in path 2 of RRN-A

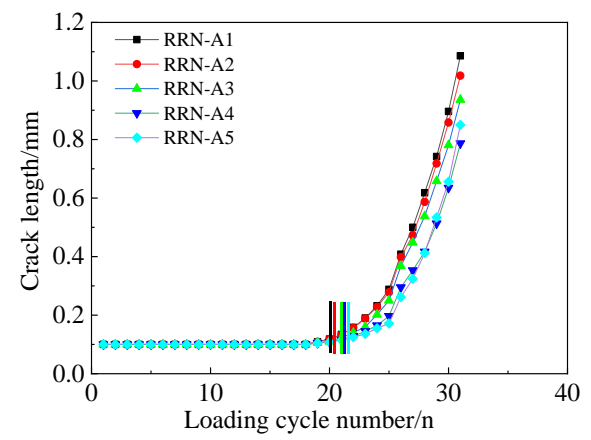

(a) point $\mathrm{A}$

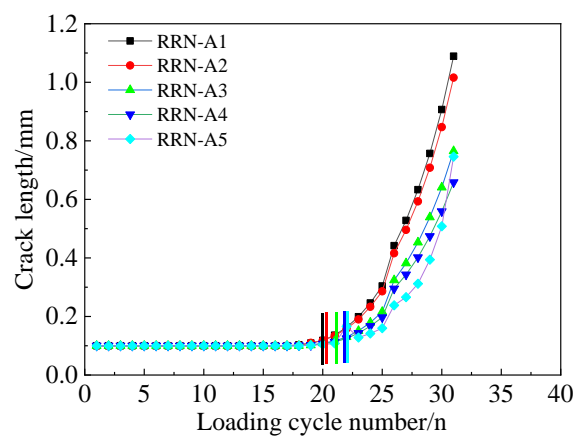

(b) point B

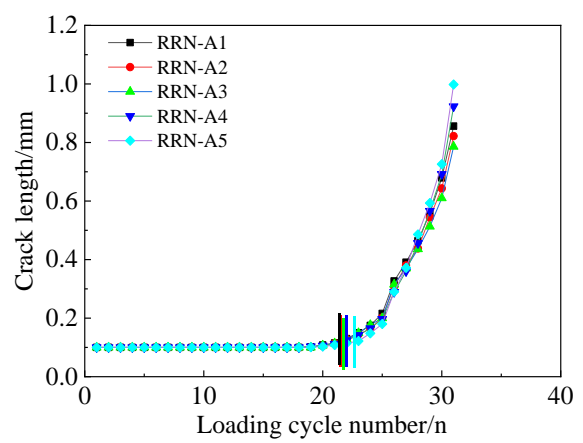

(c) point $\mathrm{C}$

Fig. 17 Crack development at key points in RRN-A

The stress triaxiality curves of RRN-A in path 1 have an "M" fluctuation along the length of the weld, which indicates that there is a high possibility of brittle fracture near the rib between the reinforced ribs. The maximum value (1.06) of RRN-A1 is slightly higher than that of the other four values. The values of $R_{\sigma}$ decrease with increasing rib length. However, the decrease in the three indexes is not obvious when the rib length increased to $175 \mathrm{~mm}$. Compared with the stress triaxiality curves for path 1 , the " $\mathrm{M}$ " fluctuation 
along the beam end of the stress triaxiality curves in path 2 is more complex. The maximum value of $R_{\sigma}$ is at one side of the rib of RRN-A5, which is 0.79 and is near the mid-beam point. The maximum value of the equivalent plastic strain index curves in path 1 is larger than that in path 2, which indicates that the middle of path 1 has a greater possibility of brittle cracking. Therefore, a reasonable length of the reinforced rib is $0.60 \sim 0.70 h_{b}$

The equivalent plastic strain index curves of RRN-A in path 1 show a "W" shape along the length of the weld, which means that the weld at both ends of the weld and in the middle of the weld has a great possibility of cracking. The value of RRN-A1 is mostly higher than that of the other four values, especially the maximum value (7.92), which is close to the right end of the beam. Besides, the maximum value of the middle weld is between 5.95 and 7.26 , indicating that the cracking possibility of the right end of the weld is the highest. The equivalent plastic strain index curves of RRN-A in path 2 have an inverted "V" fluctuation along the beam. Unlike that in path 1 , the maximum value is in RRN-A5 not in RRN-A1, which is 15.13. Besides, the value of the equivalent plastic strain index in the middle of the beam is higher than that of the other parts. Furthermore, the maximum value of the equivalent plastic strain index curves in path 2 is larger than that in path 1 , which indicates that the close-middle in path 2 has a greater possibility of cracking. Thus, a reasonable length of the reinforced rib is $0.60 \sim 0.70 h_{b}$.

The cracking index curves of RRN-A in path one also show a "W" shape along the length of the weld, which means that the weld at both ends of the weld or in the middle of the weld has a great possibility of cracking. Through analyzing the values of RRN-A in path 1, the crack probability in the middle of the weld is higher than that of the others because the maximum value (33.69) of RRN-A1 is higher than that (30.50) of RRN-A2. The cracking index curves of RRN-A in path 2 show an inverted " $\mathrm{V}$ " shape along the beam width. The maximum value (47.13) is in RRN-A5, which is close to the mid-beam point. Comparing the maximum value of the two diagrams, the cracking possibility at the mid-beam point in RRN-5 is largest because its maximum value is larger than that of RRN-A1. Therefore, a reasonable length of the reinforced rib is $0.60 \sim 0.70 h_{b}$.

Fig. 17 shows the crack length development curves of three key points of RRN-A. With increasing reinforced rib length, the cracking time is gradually delayed, but the crack length increases. After entering the fifth stage of loading (the 22nd circle), the slope of each crack length development curve at points $\mathrm{A}$ and $\mathrm{B}$ rises rapidly, but the curves at point $\mathrm{C}$ rise slowly. The longest crack lengths at points $\mathrm{A}, \mathrm{B}$, and $\mathrm{C}$ are $1.07,1.09$, and 1.02, respectively. The crack length at point $\mathrm{A}$ and point $\mathrm{B}$ of RRN-A1 is the longest and that of RRN-A2 is the second longest, but the crack length at point C of RRN-A5 is the longer than that of RRN-A2. According to the above analysis of the cracking index, the crack probability of the weld at point $\mathrm{B}$ is highest. The final crack lengths of RRN-A1, RRN-A2, RRN-A3, RRN-A4, and RRN-A5 at point $B$ are $1.09 \mathrm{~mm}, 1.02 \mathrm{~mm}, 0.77 \mathrm{~mm}, 0.66 \mathrm{~mm}$, and $0.75 \mathrm{~mm}$, respectively. The cracking times of RRN-A3, RRN-A4, and RRN-A5 are later than those of the other two. Consequently, a reasonable length of the reinforced rib is $0.60 \sim 0.75 h_{b}$.

In summary, a reasonable length of the reinforced rib of the double-ribbed reinforced beam-column connections of $0.60 \sim 0.70 h_{b}$ was determined through studying the stress triaxiality ratio $\left(R_{\sigma}\right)$, plastic equivalent strain index $(P . I$.$) , cracking index (R.I.), and crack development at three key points.$

\subsection{Influence of $b$}

Similar to the analysis of la, the elastic-plastic fracture indexes $\left(R_{\sigma}, P I\right.$, and R.I.) of RRN-B derived from ABAQUS are shown in Fig. 18, Fig. 19, and Fig. 20, respectively. Compared with the $R_{\sigma}$ curves of RRN-A, the curves of the stress triaxiality ratio of RRN-B in Fig. 18 and Fig. 19 are similar to those of RRN-A. The stress triaxiality curves of RRN-B in path one also have an "M" fluctuation along the length of the weld, which indicates that the possibility of brittle cracking of the weld near the rib between the two ribs is high. Although the maximum value (1.02) is in RRN-B5, the maximum values of these five curves are very close (the error is within 5\%). Similar to the stress triaxiality curves of RRN-A in path 2, the shape of the "M" fluctuation along the beam end is slanted. Similarly, the maximum value $(0.74)$ is in RRN-B5, but the maximum value of these five curves is still very close (the error is within 5\%). Therefore, it is difficult to analyze the influence of $b$ by discussing the stress triaxiality ratio.

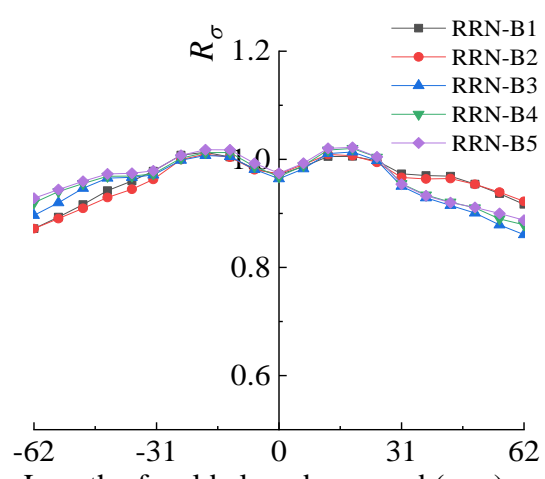

Length of weld along beam end (mm)

(a) Stress triaxiality ratio

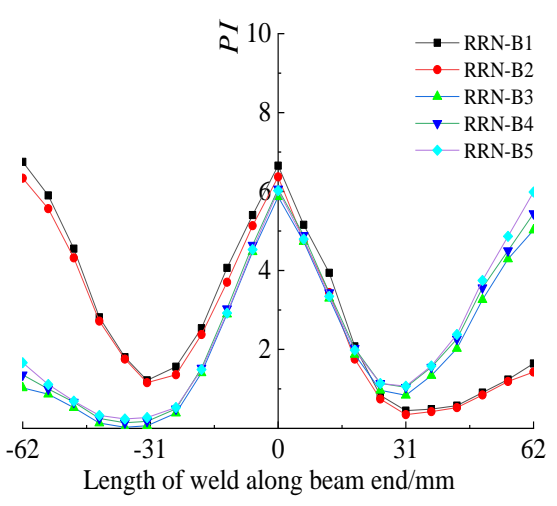

(b) Equivalent plastic strain index

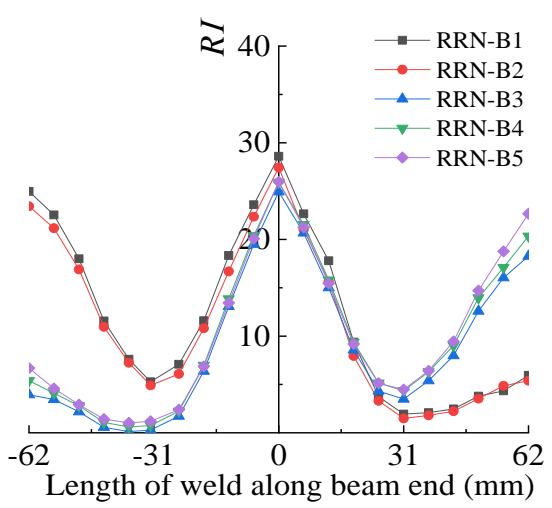

(c) Cracking index

Fig. 18 Parameters about fracture assessment in path 1 of RRN-B

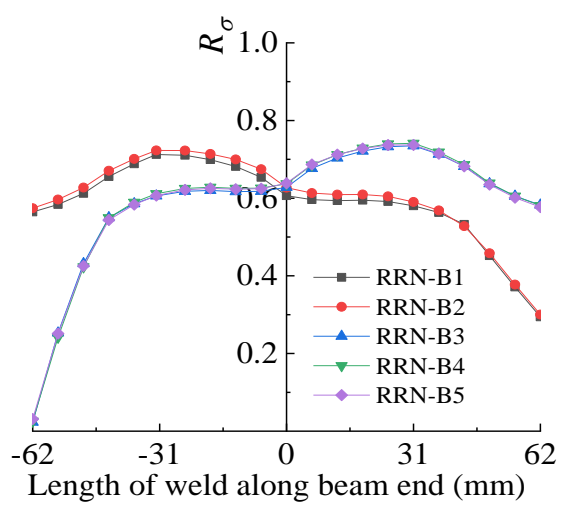

(a) Stress triaxiality ratio 


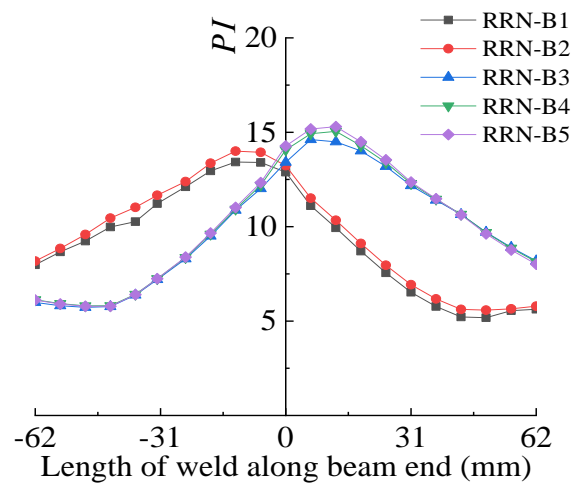

(b) Equivalent plastic strain index

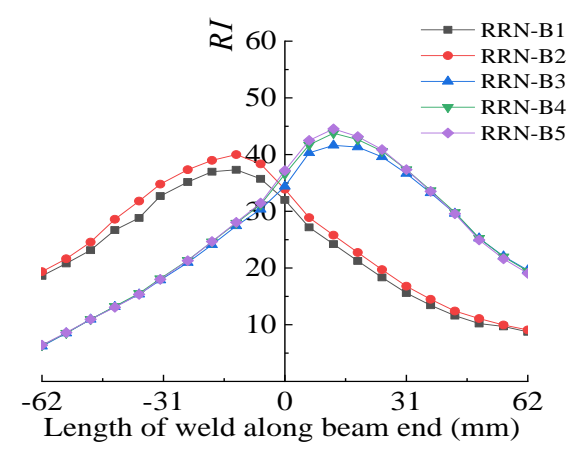

(c) Cracking index

Fig. 19 Parameters about fracture assessment in path 2 of RRN-B

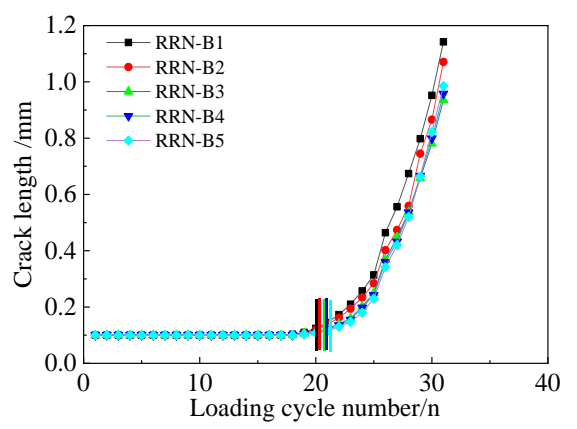

(a) point $\mathrm{A}$

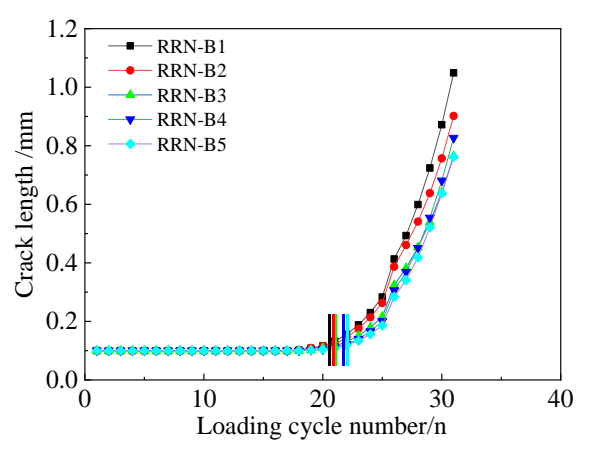

(b) point $\mathrm{B}$

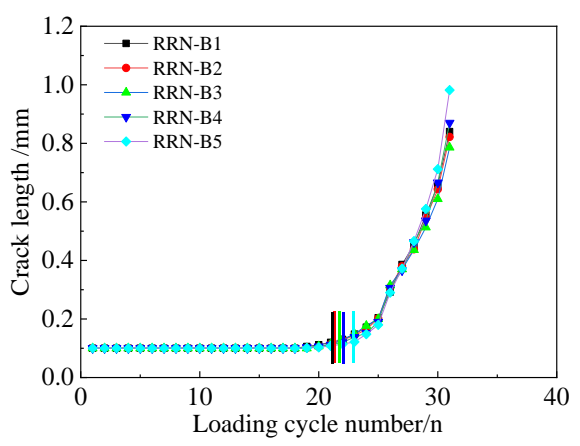

(c) point $\mathrm{C}$

Fig. 20 Crack development at key points in RRN-B

In the same way, the equivalent plastic strain index curves of RRN-B in path one also show a "W" fluctuation along the length of the weld. The value of RRN-B1 is mostly higher than that of the other four values, and the maximum value is 6.75 . Besides, the value of the P.I. in the middle part of the weld is between 5.87 and 6.67 , indicating that the change in the rib width has some influence on the cracking condition of path 1 . Regarding the equivalent plastic strain index curves of RRN-B in path 2, the shape of these curves along the beam is similar to that of RRN-A in path 1 . The maximum value (15.30) is in RRN-A5, which is close to the midpoint of the beam. Meanwhile, the error among RRN-B3, RRN-B4, and RRN-B5 is small, and the maximum value of these three curves is also higher than that of the other two curves. Compared with the maximum value of the equivalent plastic strain index curves in the path, the maximum value of the equivalent plastic strain index curves in path 2 is larger, which means that the near-middle in path 2 has a greater possibility of cracking. Therefore, a reasonable width of the double ribs is $0.50 \sim 0.60 a$.

Similarly, the cracking index curves of RRN-A in path one also show a "W" shape along the length of the weld, which means that the weld at both ends of the weld or in the middle of the weld has a great possibility of cracking. Through analyzing the values of RRN-B in path 1 , the crack probability in the middle of the weld is higher than that of the others because the maximum value (28.60) of RRN-B1 is higher than that of the others. The cracking index curves of RRN-A in path 2 show an inverted "V" shape along the beam width. The maximum value (44.54) is in RRN-B5, which is close to the mid-beam point. Comparing the maximum value of the two diagrams, the cracking possibility at the mid-beam point in RRN-5 is largest because its maximum value is larger than that of RRN-A1. Therefore, a reasonable length of the reinforced rib is $0.45 \sim 0.55 a$.

The crack length development curves of three key points of RRN-B are shown in Fig. 20, which have the same trend as that of RRN-A. After entering the fifth stage of loading (the 20th cycle), the slope of each crack length development curve at point $\mathrm{A}$ rises rapidly, but the curves at points $\mathrm{B}$ and $\mathrm{C}$ rise slightly later, and the longest crack lengths at points $\mathrm{A}, \mathrm{B}$, and $\mathrm{C}$ are 1.12 $\mathrm{mm}$ (RRN-B1), $1.05 \mathrm{~mm}$ (RRN-B1) and $0.91 \mathrm{~mm}$ (RRN-B5), respectively. According to the above analysis of the cracking index, the crack probability of the weld at point $\mathrm{A}$ is the highest. The final crack lengths of RRN-B1, RRN-B2, RRN-B3, RRN-B4, and RRN-B5 at point B are $1.12 \mathrm{~mm}, 1.05 \mathrm{~mm}$, $0.93 \mathrm{~mm}, 0.94 \mathrm{~mm}$, and $0.98 \mathrm{~mm}$, respectively. Besides, the cracking times of RRN-B3, RRN-B4, and RRN-B5 are later than those of the other two. As a result, a reasonable width of the reinforced rib is $0.50 \sim 0.60 a$.

In summary, a reasonable length of the reinforced rib of the double-ribbed reinforced beam-column connections is difficult to obtain by studying the stress triaxiality ratio $\left(R_{\sigma}\right)$ because the error between the values of the five models is very small. However, a reasonable length of the reinforced rib of the double-ribbed reinforced beam-column connections is $0.50 \sim 0.55 a$, which is determined by studying the plastic equivalent strain index (P.I.), cracking index (R.I.), and crack development at three key points.

\subsection{Influence of $t_{s}$}

The curves of the elastic-plastic fracture indexes $\left(R_{\sigma}, P I\right.$, and R.I. ) of the RRN-C group model are presented in Figs. 21-23, respectively. Compared with the $R_{\sigma}$ curves of RRN-A and RRN-B, the curves of the stress triaxiality ratio of RRN-C in Fig. 21 and Fig. 22 are more regular than those of the other two, and the shape of the curves looks like a wave along the length of the weld. The values of all stress triaxiality curves of RRN-Care between 0.87 and 1.04 , and the maximum value (1.04)is in RRN-C1 near the reinforced rib, which indicates that the possibility of brittle cracking of the weld near the rib 
is high. The values of RRN-C3, RRN-C4, and RRN-C5 are relatively smaller than those of RRN-C1 and RRN-C2, which indicates that the crack probability of RRN-C1 is highest among these five models. Concerning the curves of the stress triaxiality ratio in path 2 , these curves also show an " $\mathrm{M}$ " fluctuation along the width of the beam, but they tilt left. The maximum value $(0.81)$ near the right rib is in RRN-C5, and the values of RRN-C5 are significantly higher than those of the other four values, which means that the crack probability near the right reinforced rib of RRN-C5 is the highest among these five models. As a result, the reasonable thickness ts of the double ribs is $1.50 \sim$ $1.60 t_{f}$ by discussing the stress triaxiality ratio $\left(R_{\sigma}\right)$.

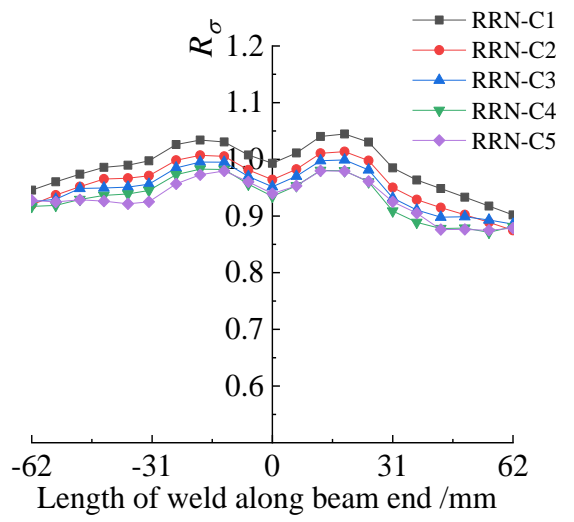

(a) Stress triaxiality ratio

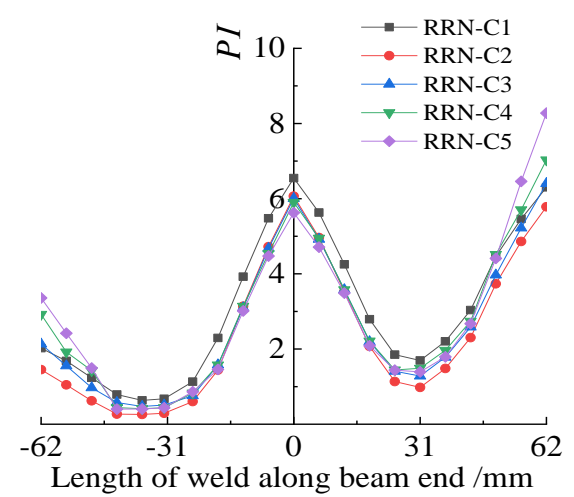

(b) Equivalent plastic strain index

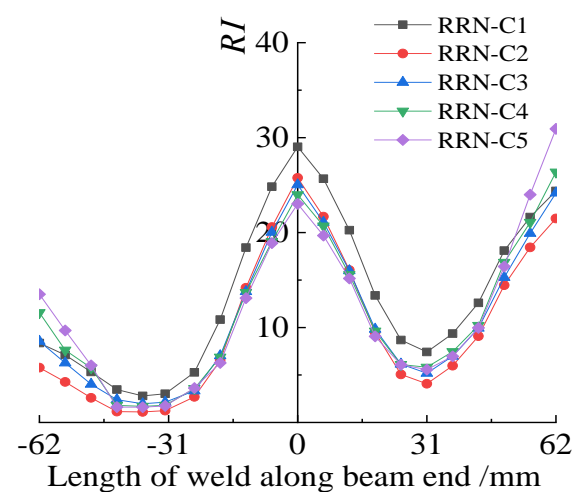

(c) Cracking index

Fig. 21 Fracture assessment parameters in path 1 of RRN-C

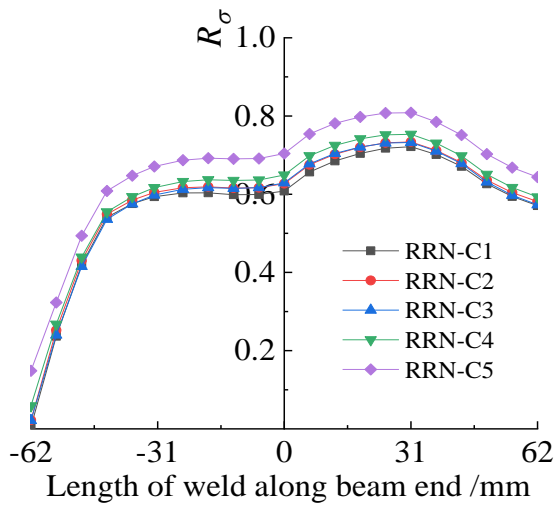

(a) Stress triaxiality ratio

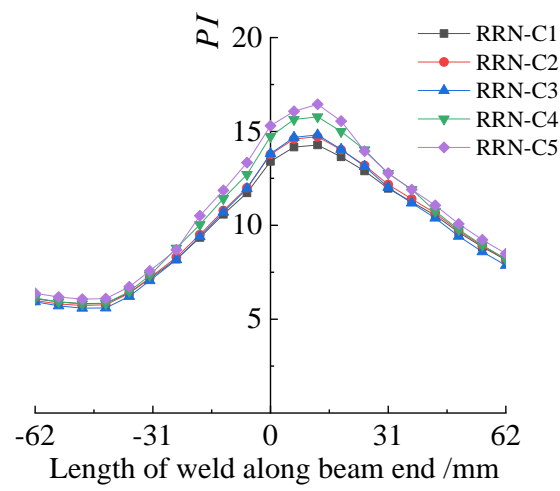

(b) Equivalent plastic strain index

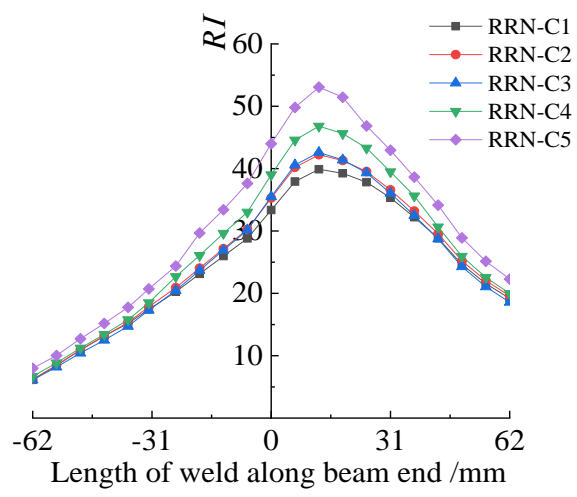

(c) Cracking index

Fig. 22 Parameters of fracture assessment in path 2 of RRN-C

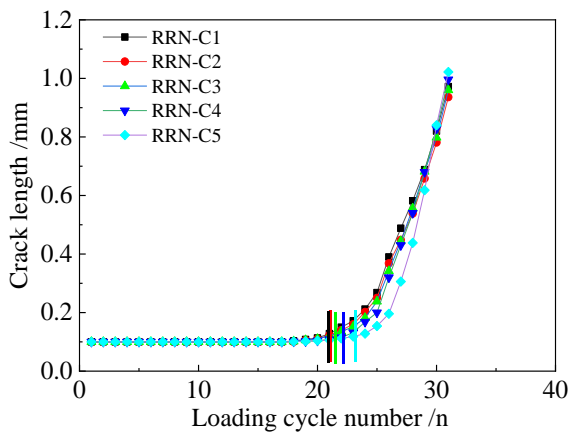

(a) point $\mathrm{A}$ 


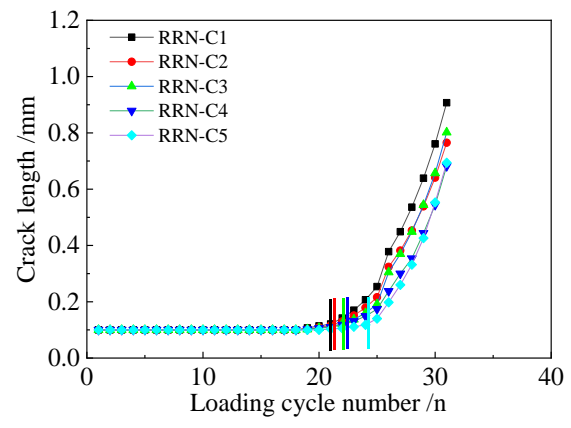

(b) point B

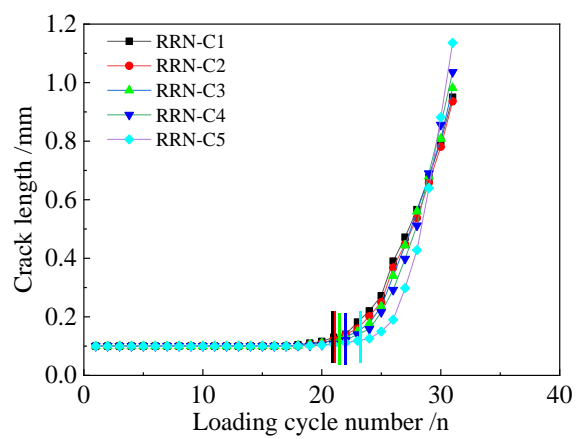

(c) point $\mathrm{C}$

Fig. 23 Development of crack at key points in RRN-C

In Fig. 21(b), the curves of the equivalent plastic strain index of the RRN-C in path one also show a "W" fluctuation with low left and high right along the length of the weld. The value of RRN-C1 is partly higher than that of the other four values, but the maximum value (8.28) at the right end of the weld is in RRN-C4. This indicates that the crack probability of the right end of the weld is the highest. However, the shape of the equivalent plastic strain index curves of RRN-B in path 2 is different from that of RRN-C in path 1, and they are similar to those of RRN-A and RRN-B in path 2. The maximum value (16.45) is in RRN-C5, which is close to the midpoint of the beam, followed by RRN-C4 (15.78). Meanwhile, the error among RRN-B3, RRN-B4, and RRN-B5 is small, and the maximum value of these three curves is also lower than that of the other two curves. Therefore, a reasonable thickness $t_{s}$ of the double ribs is $1.40 \sim 1.60 t_{f}$, determined by discussing the equivalent plastic strain index.

The curves of the cracking index (R.I.) in path 1 of RRN-C in Figs. 21(c) and 22(c) are similar to those of RRN-A and RRN-B, respectively. From Fig. 21(c), the crack probability of the right end of the weld is higher than that of the mid-weld because the maximum value (30.92) of RRN-C5 is higher than that (28.8) of RRN-C4. The error among the other three models is relatively small. Similarly, in Fig. 22, the maximum value (53.08) is in RRN-C5, and the second largest value (46.81) is in RRN-C4. Therefore, a reasonable thickness $t_{s}$ of the double ribs is $1.40 \sim 1.70 t_{f}$ based on the cracking index.

The crack length development curves of the three key points of RRN-C are shown in Fig. 23, which have the same trend as those of RRN-A and RRN-B. After entering the fifth stage of loading (the 21st circle), the slope of each crack length development curve at three points rises rapidly. The shape of the curves at point $C$ is the largest and that of the curves at point $B$ is the smallest. Besides, the longest crack lengths at points $\mathrm{A}, \mathrm{B}$, and $\mathrm{C}$ are $1.06 \mathrm{~mm}$ (RRN-C5), $0.92 \mathrm{~mm}$ (RRN-C1), and $1.15 \mathrm{~mm}$ (RRN-C5), respectively. However, the time to start cracking of RRN-C5 at the three points is later than that of the other models and that of RRN-C1 at the three points is the earliest. According to the above analysis of the cracking index, point $\mathrm{C}$ is the most dangerous among the three points, which means that RRN-C2, RRN-C3, and RRN-C4 are relatively safe. The final crack lengths of RRN-C1, RRN-C2, RRN-C3, RRN-C4, and RRN-C5 at point B are $0.93 \mathrm{~mm}, 0.92 \mathrm{~mm}, 0.98 \mathrm{~mm}$, $1.02 \mathrm{~mm}$, and $1.15 \mathrm{~mm}$, respectively. Thus, a reasonable thickness of the reinforced rib is $1.40 \sim 1.60 t_{f}$.

In summary, a reasonable thickness of the reinforced rib of the double-ribbed reinforced beam-column connections is $1.50 \sim 1.60 t_{f}$, which is determined by studying the stress triaxiality ratio $\left(R_{\sigma}\right)$, plastic equivalent strain index (P.I.), cracking index (R.I.) and crack development at three key points.

\section{Conclusions}

Based on the experimental and numerical analytical results, the FE model of a double-ribbed reinforced beam-column connection is verified. Using the stress triaxiality ratio $\left(R_{\sigma}\right)$, the plastic equivalent strain index $(P . I$.$) , cracking$ index (R.I.), and crack development at three key points, reasonable parameters of the reinforced ribs of the double-ribbed reinforced beam-column connections are suggested. The following conclusions are drawn:

(1) Compared to conventional connections, double-ribbed reinforced beam-column connections have a higher damage modulus and ultimate bearing capacity with increasing cumulative displacement, and the reinforced ribs can effectively move the plastic hinge away from the beam end.

(2) For the hysteretic behavior, the hysteresis curves of the two specimens and the two finite element models are basically consistent at the initial loading stage and gradually become different due to the existence of stress concentrations, processing errors, and uneven material in the specimens. Due to the existence of the reinforced ribs, the average value of the ductility coefficient of the RRN is higher than that of the NBN, and the energy dissipation coefficient of the RRN is higher than that of the NBN.

(3) From the comprehensive analysis of the stress triaxiality ratio $\left(R_{\sigma}\right)$, equivalent plastic strain index (P.I.), cracking index (R.I.), and crack development at three key points, reasonable parameters for the ribs of the double-ribbed reinforced connections are given as follows: $l_{a}=0.60 \sim 0.70 h_{b}$; $b=0.50 \sim 0.55 a$; and $t_{s}=1.50 \sim 1.60 t_{f}$.

\section{Acknowledgments}

The authors appreciate the support of the National Science Foundation of China (51708485, 51878589 and 51878590), the Natural Science Foundation of Jiangsu Province (BK20191441), the Jiangsu Planned Projects for Postdoctoral Research Funds (1701191B), the Science and Technology projects of Ministry of Housing and Urban-rural Development (2014-K2-045 and 2014-K2-022), the China Postdoctoral Science Foundation (2017M611925), the Talent Plan of Innovate and Entrepreneurship in Jiangsu Province and the Talent Plan of Yangzhou City.

\section{References}

[1] Shen Z., Chen Y., Chen Y. and Zhao X., "Basic principle of steel structure," China Architecture \&Building Press, 2018

[2] White D. W. and Chen W. F., "Organization and summary of discussions at the US-Japan seminar on innovations in stability concepts and methods for seismic design in structural steel," Engineering Strutures, 20(4-6), 242-248, 1998.

[3] Miller D. K., "Lessons learned from the Northridge earthquake," Engineering Strutures, 20(4-6), 249-260, 1998

[4] Saher E. K., Sakr M. A., Khalifa T. M. and Eladly, M.M., "Modelling and behavior of beam-to-column connections under axial force and cyclic bending," Journal of Constructional Steel Research, 129, 171-184, 2017.

[5] GB50017-2017, Standard for the design of steel structures, China Construction Industry Press, 2017.

[6] Guo B., Gu Q. and Liu F., "Experiment behavior of stiffened and unstiffened end-plate connections under cyclic loading," Journal of Structural Engineering, 132(9), 1352-1357. 2006.

[7] Pachoumis D. T, Galoussis E. G., Kalfas C. N. and Christitsas A. D., "Reduced beam section moment connections subjected to cyclic loading: Experimental analysis and FEM simulation," Engineering Strutures, 31(1), 216-223, 2009.

[8] Sophianopoulos D. S. and Deri, A. E., "Parameters affecting response and design of steel moment frame reduced beam section connections: An overview," International Journal of Steel Structures., 11(2), 133-144, 2011.

[9] Han S. W., Moon K. H., Hwang S. H. and Stojadinovic B., "Rotation capacities of reduced beam section with bolted web (RBS-B) connections," Journal of Constructional Steel Research, 70, 256-263, 2012.

[10] Swati A. K. and Vesmawal G., "Study of steel moment connection with and without reduced beam section," Case Studies in Engineering Structures, 1, 26-31, 2014.

[11] Oh K. Y., Lee K. M., Chen L. Y., Hong S. B. and Yang Y., "Seismic performance evaluation of weak axis column-tree moment connections with reduced beam section," Journal of Constructional Steel Research, 105, 28-38, 2015.

[12] Rahnavard R., Hassanipour A. and Siahpolo N., "Analytical study on new types of reduced beam section moment connections affecting cyclic behavior," Case Studies in Structural Engineering, 3, 33-51, 2015 .

[13] Soliman A. A., Ibrahim O. A. and Ibrahim A. M., "Effect of panel zone strength ratio on reduced beam section steel moment frame connections," Alexandria Engineering Journal, $57,3523-3533,2018$

[14] Nia M. M. and Moradi S., "Effects of design factors on the cyclic response of shaped RBS moment connections," Engineering Structures, 207, 1-16, 2020

[15] Engelhardt M. D. and Sabol T. A., "Reinforcing of steel moment connections with cover plates: benefits and limitations," Engineering Structures, 20(4-6), 510-520, 1998.

[16] Chen C. C., Lin C. C. and Tsai C. L., "Evaluation of reinforced connections between steel beams and box columns," Engineering Structures, 26(13), 1889-1904, 2004

[17] Ghobadi M. S., Mazroi A. and Ghassemieh M., "Cyclic response characteristics of retrofitted moment-resisting connections", Journal of Constructional Steel Research, 65, 586-598, 2009.

[18] Erfani S., Asnafi A. A. and Goudarzi A., "Connection of I-beam to box-column by a short stub beam," Journal of Constructional Steel Research, 127, 136-150, 2016.

[19] Yang L. and Chen H., "Mechanical performance of beam-column joint with widened beam 
flange," Journal Shenyang University of Technology, 39(4), 459-463, 2017 (in Chinese).

[20] Tian Y., Liu M., Jia Z. and Dai Y., "Study on mechanical behavior and optimization of prefabricated square column H-beam outer-shell joint," Mechanics of Advanced Materials and Structures, 27, 409-416, 2019.

[21] Ma H. W., Wang J. W., Lui E. M., Wang K. and Wan Z. Q., "Experimental study of the behavior of beam-column connections with expanded beam flanges," Steel and Composite Structures, 31, 319-327, 2019.

[22] Wang Z. X. and Shi H. J., "Effect of the stress triaxiality on the ductile fracture," Chinese Journal of Materials Research, 21, 170-176, 2007.

[23] Shi Y., Shi G., Wang Y. and Chen H., "Beam-column joints of multi high rise steel frame -Theory and design," China Architecture \& Building Press, 2014.

[24] Wang Y., "A seismic design theory and application of new ductility joint of steel structure," China Science Publishing Media Ltd, 2012.

[25] Hamburger R. O., Hooper J. D., Sabol T., et al., "FEMA-350 recommended seismic design criteria for new steel moment-frame buildings", Washington D. C.: The Federal Emergency Management Agency, 2000

[26] Steel and Steel Products Location and Preparation of Test Pieces for Mechanical Testing 2017, China Architecture \& Building Press, Beijing, China, 2017.

[27] Metallic Materials Tensile Testing 2010. China Architecture \& Building Press, Beijing, China, 2010 .

[28] Specification for Seismic Test of Buildings 2015. China Architecture \& Building Press, Beijing, China, 2015.

[29] ABAQUS/Standard User Subroutines Reference Manual 1998. The Pennsylvania State University, USA, 1998.

[30] Amar K., "Introduction to finite element analysis using MATLAB and ABAQUS," Taylor \& Francis Group, 2013.

[31] Song Z., "Cumulative Damage Failure Mechanism and Seismic Design Countermeasures for Rigid Beam-column Connections in Steel Frames under Earthquake Action," Xi'an University of Architecture and Technology, Xi'an, China, 2001.

[32] Narita S., Hyakawa K., Uenori T. and Kubota Y., "Evaluation of strength of stainless steel bolt without heat treatment considering Bauschinger effect during the manufacturing process", Journal of Materials Processing Technology, 278, 116481, 2020.

[33] Ma H. W., Zhao Y., Wang Z. J. and Chen Y. K., "Hysteretic behavior analysis of new beam-column connections with the expanded flange of the steel frame," Journal of Yangzhou University, 20(4-6), 242-248, 2018.

[34] Kumar S. and Usami T. "A note on the evaluation of damage in steel structures under cyclic loading", Journal of Structural Engineering, 40, 177-178, 1998.

[35] Schafer B. W., Ojdrovic R. P. and Zarghamee M. S., "Triaxiality and fracture of steel moment connections," Journal of Structural Engineering, 126, 1131-1139, 2000

[36] EI-Tawil S., Mikesell T. and Kunnath S. K., "Effect of local details and yield ratio on the behavior of FR steel connections," Engineering Structures, 126(11), 79-87, 2000.

[37] Hancock J. W. and MacKenzie A. C. "On the mechanisms of ductile failure in high strength steel subject to multi-axial stress-states." Journal of the Mechanics and Physics of Solids, 24, 147-169, 1976.

[38] Mao C., Ricles J., Lu L. and Fisher J., "Effect of local details on the ductility of welded moment connections," Journal of Structural Engineering, 127, 1036-1044, 2001. 